\title{
Dysfunctional vascular smooth muscle cells mediate early and late-stage neuroinflammation and Tau hyperphosphorylation
}

Jorge A. Aguilar-Pineda $\mathrm{PhD}^{2^{*}}$., Karin J. Vera-Lopez PharmD, $\mathrm{PhD}^{2^{*}}$., Pallavi Shrivastava $\mathrm{PhD}^{2}$., Rita Nieto-Montesinos PharmD, $\mathrm{PhD}^{2}$., Miguel A. Chávez-Fumagalli $\mathrm{PhD}^{2}$., Gonzalo Davila Del-Carpio PharmD, PhD²., Badhin Gomez Valdez PhD²., Clint L. Miller, PhD³., Rajeev Malhotra MD, MS ${ }^{1}$., Mark E. Lindsay MD, $\mathrm{PhD}^{1}$., Christian L. Lino Cardenas PharmD, MSc, $\mathrm{PhD}^{2 \#}$.

1 Cardiovascular Research Center, Cardiology Division, Massachusetts General Hospital, Boston, Massachusetts, USA 02114.

2 Laboratory of Genomics and Neurovascular Diseases, Vicerrectorado de investigacion, Universidad Catolica de Santa Maria, Arequipa, Peru.

3 Center for Public Health Genomics, Department of Public Health Sciences, University of Virginia, Charlottesville, VA, USA 22908.

* Authors contributed equally to this manuscript.

\# Corresponding authors

Please send correspondence to clinocardenas@mgh.harvard.edu \& kvera@ucsm.edu.pe 


\section{SUMMARY}

Despite the emerging evidence implying early vascular contributions to neurogenerative syndromes, the role of vascular smooth muscle cells (VSMCs) in the pathogenesis of Alzheimer's disease is still not well understood. Herein, we show that VSMCs in brains of AD patients and the animal model of the disease, are deficient in multiple VSMC-contractile markers which correlated with Tau accumulation in brain arterioles. Ex vivo and in vitro experiments demonstrated that VSMCs undergo dramatic phenotypic transitions under AD-like conditions, adopting pro-inflammatory and synthetic phenotypes. Notably, these changes coincided with Tau hyperphosphorylation at residues Y18, T205 and S262. We also observed that loss of VSMC markers occurred in an age-dependent manner, and that expression of Sm22 $\alpha$ and $\alpha-S m a$ proteins were inversely correlated with CD68 and Tau accumulation in brain arterioles of $3 \times T g-A D$ mice. Together, these findings further support the contribution of VSMCs in $A D$ pathogenesis, and nominate VSMCs as potential novel therapeutic target in AD.

\section{Graphical Abstract}

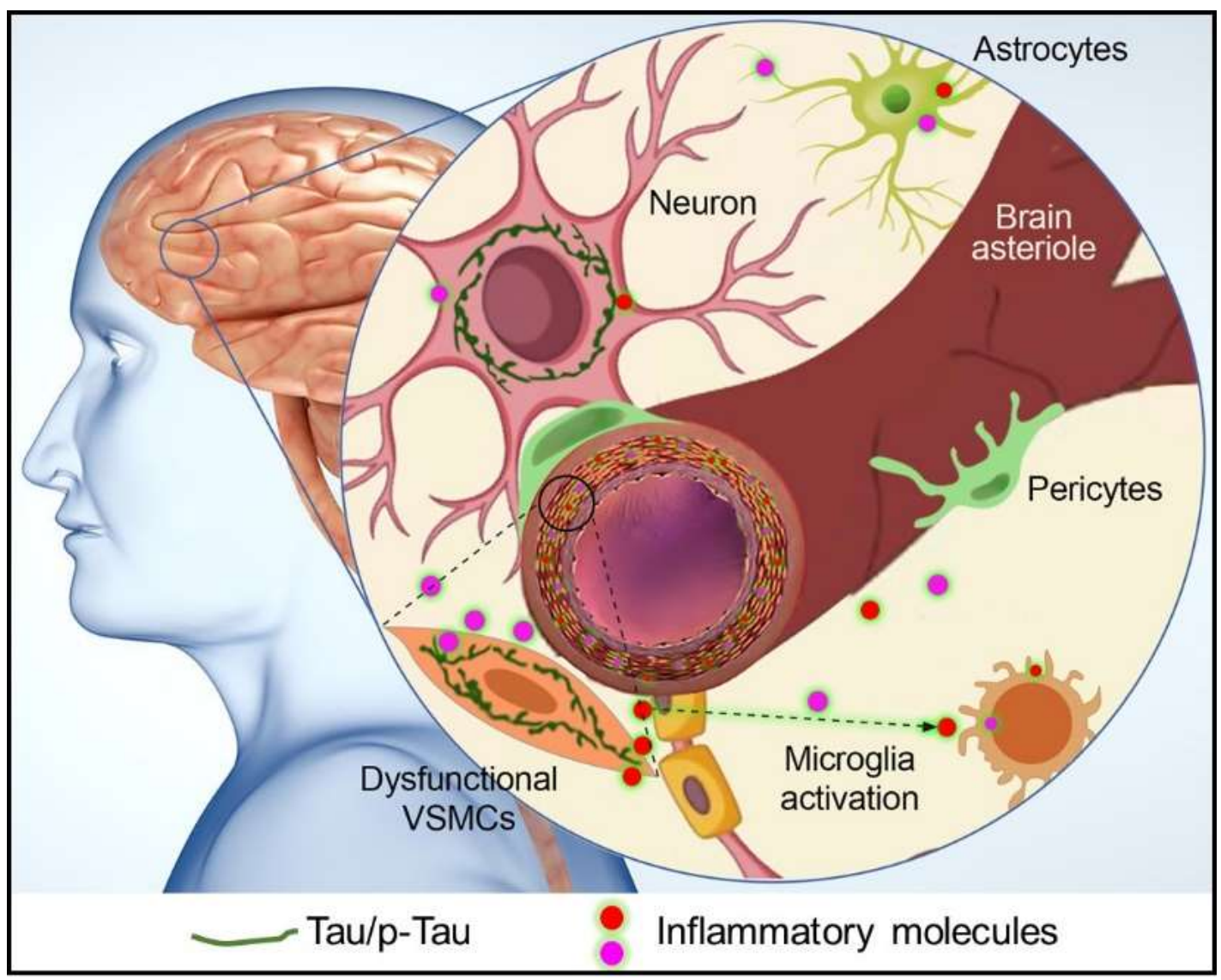




\section{INTRODUCTION}

Alzheimer's disease $(A D)$ is a debilitating neurological disorder that leads to cognitive decline and dementia. The prevalence of AD patients is predicted to surge more than $150 \%$ in the next decade, in line with the increased aging in US population (>65 years old) (Morris et al., 2020; Alzheimer's Association 2018). Tau neurofibrillary tangle (NFT) deposits are characteristic hallmarks of $A D$ and it correlates closely with cognitive decline which begins to develop around two decades before clinical manifestations (Nirzhor et al., 2018; Leszek et al., 2013; Barthélemy et al., 2020). The microtubule-associated Tau protein (MATP) plays a key role in the morphogenesis and homeostasis of mature neurons. Also, multiple residues in the Tau protein ( 80 aa) undergo post translational modifications (PTMs), which are critical for proper assembly and stability of the microtubule cytoskeleton, transport of nutrients, protein synthesis, neuroprotection, and apoptosis (Wesseling et al., 2020). However, aberrantly increased levels of soluble Tau protein often leads to intracellular toxicity. Likewise, excessive phosphorylation results in the self-assembly of tangles and straight filaments, which are involved in the physiopathogenesis of AD-related neurodegenerative tauopathies, such as frontotemporal dementia (FTD-tau), progressive supranuclear palsy (PSP), and corticobasal degeneration (CBD) (Lathuilière et al., 2017).

Recent proteomics studies have identified over 50 candidate Tau phosphorylation sites during Tau aggregation into neurofibrillary tangles, supporting a critical role of Tau PTMs in AD progression (Barthélemy et al., 2019; Wesseling et al., 2020). The recent discoveries of Tau hyperphosphorylation sites have led to the development of biomarkers for the diagnosis of Tauassociated diseases. Indeed, Tau hyperphosphorylation at residues T153, T205, S208 and T217 were exclusively found in CSF from AD patients (Barthélemy et al., 2019). Also, increased plasma levels of $p$-Tau (T181) were used to stratify patients with $A D$ dementia from non-AD neurodegenerative diseases (Janelidze et al., 2020). The hyperphosphorylation of residues T181 and T217 was shown to occur decades before the formation of NFT and onset of clinical symptoms (Barthélemy et al., 2020). And t-Tau and p-Tau (T205) were associated with brain atrophy, cognitive decline, and late onset of symptoms. In addition, hyperphosphorylation at Y18 residue is increased in the cortex at Braak stage V/VI in AD patients (Neddens et al., 2018). Those clinical observations indicate that phosphorylation alterations in the Tau protein follow a strict curve over the course of AD progression (Barthélemy et al., 2020). Genetically, several mutations in the Tau gene have been shown to cause neurodegenerative disorders including familial frontotemporal dementia (FTD) and progressive supranuclear palsy (PSP) and parkinsonism linked to chromosome 17 (FTDP-17) (Lopez Gonzalez et al., 2016; Morishima-Kawashima et al., 2011). The well-studied mutated Tau ${ }^{\mathrm{P} 301 \mathrm{~L}}$ was first diagnosed in six French families with frontotemporal dementia and parkinsonism (Dumanchin et al., 1998), and has since been found in approximately 32 families around the world (Tsuboi et al., 2004; Kowalska et al, 2009). This proline to leucine substitution causes Tau aggregation and develops numerous intracytoplasmic tau deposits in multiple brain regions, including the hippocampus, neocortex, and substantia nigra (Giménez-Llort et al., 2008). 
Vascular dementia (VD) is the second most common subtype of dementia after AD, accounting for $15-30 \%$ of dementia cases globally (Lobo et al., 2000; Rizzi et al., 2014; Jhoo et al., 2008; Chan et al., 2013; Kalaria et al., 2008). Recent epidemiological studies have established a link between AD and cardiovascular disease risk factors (Lamar et al., 2020) (e.g., hypertension, atherosclerosis, obesity, type 2 diabetes, etc.) suggesting that the neurovascular units (NVU) may contribute to the initiation and progression of AD (Zlokovic et al., 2011; Kim et al., 2020). These emerging data suggest that $A D$ is a multifactorial, multi-organ disease with triggers beyond the CNS unit including vascular dysfunction and inflammation, which may precede neuropathological changes (De la Torre et al., 2018). In this context, Vascular smooth muscle cells (VSMCs) may play fundamental roles in regulating disease processes underlying both cardiovascular disease (CVDs) and AD (Frismantiene et al., 2018 and Mok et al., 2006).

VSMCs are highly plastic cells in the vessel wall (Castro et al., 2018; Rong et al., 2003) and readily transition from a contractile state to a synthetic or transdifferentiated entity in response to a wide range of pathogenic stimulus (Wang et al., 2015; Owens et al., 1995; Kalaria, 2003; Erkinjuntti et al., 2004). Transdifferentiated VSMCs are often characterized by loss of expression in contractile markers which are required to maintain the healthy vascular tone of brain arterioles. During vessel injury, VSMC phenotype switching is induced by various proinflammatory cytokines (i.e., interleukins and TNFa) (Tyrrell et al., 2021) or growth factors (i.e., PDGFs and FGFs) (Claesson-Welsh., 1996; Kendrick et al., 2011). Interestingly, synthetic VSMC-secreted proteins are associated with known neurogenerative markers, including the production of Coffilin-1, matrix metallopeptidase 9 (MMP9) and proinflammatory signals, such as CD68, IL-6, VCAM-1, ICAM-1 and MCP-1 (Lino Cardenas et al., 2019; Lee et al., 2013; Li et al., 2020). Therefore, there is a critical need to resolve the causal role of VSMCs and vascular dysfunction underlying AD progression. In this study we show that dysfunctional VSMCs can contribute to the $A D$ development through the production of neuroinflammatory molecues including CD68, MMP9 and IL-6. We also show that VSMCs can generate elevated quantities of Tau protein as well induce its hyperphosphorylation at multiple sites, further implicating VSMCs in the initiation and progression of AD pathogenesis. 


\section{RESULTS}

\section{Dysfunctional VSMCs contribute to brain inflammation and Tau hyperphosphorylation.}

The role of brain-VSMCs in neuroinflammation and Tau hyperphosphorylation is poorly understood. Thus, we performed a transcriptomics analysis of previously described markers of VSMC phenotypic state from healthy and AD human brains (Bennett et al., 2014). Interestingly, AD-brains exhibited an up-regulation of synthetic-VSMC genes including GJA, S100A4, CALD1 and PDGFRB (known to be a potent inducer of VSMC phenotype switching). Remarkably, genes that associated with vascular-related diseases including LTBP3 (aortic dissection) (Guo et al., 2018), PRKG1 (thoracic aortic aneurysm) (Isselbacher et al., 2016) and TLN1 (coronary atherosclerosis) (Li et al., 2020) were also found to be up-regulated in ADbrains (Figure 1A and S1A). In contrast, expression of VSMC contractile genes in AD-brains were almost undetectable consistent with previous observations in other forms of VSMCrelated diseases (Frismantiene et al., 2018; Owens et al., 2004; Mack, 2011). To investigate the role of VSMC phenotypic switching in neuroinflammation, we evaluated the levels of contractile proteins (SM22 $\alpha$ ) in arterioles and microvessels from brains of the humanized animal model of tauopathy and Alzheimer's disease, the 3xTg-AD mice at 23 weeks (Oddo et al., 2003). Notably we found that leptomeningeal and cortical arterioles of 3xTg-AD brains had abnormal wall thickness with lower levels of $S m 22 \alpha$, which was associated with increased levels of platelet-derived growth factor-BB (PDGFBB), a high affinity ligand for PDGFR (Figure 1B). Furthermore, $3 x T g-A D$ brains contained high levels of total Tau protein especially in brain arterioles as assessed by co-localized with Sm22a-positive VSMCs (Figure1C). To investigate whether transdifferentiation of VSMCs contributes to neuroinflammation, we treated brains from healthy mice with PDGFBB for 48hr (ex vivo) and analyzed markers of neuroinflammation by immunofluorescence. Our results showed that treated brains have elevated markers of neurotoxicity, including total Tau and CD68 (Figure 1D). Further, western blot analysis of total brain lysates with PDGFBB treatment showed a significant increase in p-Tau-S262 levels compared to control brains (DMSO, $p<0.001$ ) (Figure 1E). Quantitative proteomics analysis of PDGFBB versus DMSO treated brains revealed several AD-associated proteomic changes in these brains (Figure 1F). Pathway analyses of the proteomic data identified upregulation of multiple known AD pathways, including altered cell-to-cell signaling, neurological diseases, cell proliferation and neuroinflammatory pathways (Figure 1G). Based on these findings we then investigated the contributory portion of VSMCs in neuroinflammation and toxicity during $A D$ pathogenesis. For this experiment, we genetically labeled brain VSMCs of wild-type mice with a red fluorescent protein (TdTomato) expressed under the control of the Tagln (Sm22 $\alpha$ ) promoter (Figure 1H). Then we subjected Tagln-cre/TdTomato brains to 3 in vitro models of neuroinflammation (PDGFBB, mutant Tau ${ }^{\mathrm{P} 301 \mathrm{~L}}$ and LPS) to mimic AD-like microenvironments. Flow cytometry analysis of sorted VSMC ${ }^{\text {TdTomato }}$ from healthy brains revealed that vascular smooth muscle cells adopt a secretory phenotype compared to the DMSO controls (Figure 1I). We then quantified the inflammatory response of VSMC ${ }^{\text {TdTomato }}$ under AD-like conditions by flow cytometry using antibodies against CD68 (inflammation marker) and IL-6R (interleukin-6 receptor, a pro-inflammatory cytokine receptor). Our results demonstrate that the mutant 
TauP301L model had the highest proportion of CD68 and IL-R positive cells, followed by PDGFBB treatment. In contrast, LPS treated brains had the lowest proportion of both proinflammatory markers indicating a strong association of dysfunctional VSMCs in the inflammatory response rather than the activation of inflammatory pathways by LPS (Figure 1J). Taken together these findings provide new insights into the critical role for VSMCs in neurotoxicity.

\section{Morphological and phenotypic changes of VSMCs under AD-like conditions in vitro}

To further investigate the impact of dysfunctional VSMCs in AD disease, we used primary human VSMCs from neural crest lineage (Steinbach et al., 2016) and primary human microglia cells. The human VSMCs that were treated with PDGFBB, mutant Tau ${ }^{\text {P301L }}$ and LPS showed changes in their cytoskeleton morphology characterized by the formation of dendritic-like phenotype (lamellipodium) and loss of polarized cytoskeleton microfilaments (F-actin) (Figure 2A, top panel). These changes were associated with increased Tau and MMP9 protein expression in VSMCs under AD-like conditions (Figure 2A, lower panel). Evaluation of VSMC phenotypic markers demonstrated a significant downregulation of contractile genes including TAGLN (SM22 $\alpha), L R P 1, C N N 1$, and consistent upregulation of matrix degradation and inflammatory markers such as MMP2, MMP9, IL-6 and CD68 (Figure 2B). Like our ex vivo results, flow cytometry analyses of VSMCs under AD-like conditions show elevated inflammatory markers (CD68 and IL-6R) in PDGFBB and Tau ${ }^{\text {P301L }}$ but not with LPS treatment compared with DMSO controls (Figure 2C), suggesting that VSMCs undergo cellular reprograming, and trans-differentiation into pro-inflammatory cells to promote neuroinflammation. As chronic inflammation has been shown to trigger microglial activation (Navarro et al., 2018; Hansen et al., 2018), we also investigated the response of microglial cells to transdifferentiated VSMCs using a wound healing assay. Our results showed that under normal conditions (DMSO) microglial cells have a propensity to inhibit the migratory properties of synthetic VSMCs. However, under AD-like conditions (PDGFBB, mutant Tau P301L or LPS) microglia cells lose this ability while synthetic VSMCs displayed higher proliferation and migration activities (Figure 2C). Together these data indicates that $A D$ brains favor the reprograming of VSMCs and may alter the physiological responses of vascular tissue thereby accelerating neurotoxicity in AD brains.

\section{Dysfunctional VSMCs induce AD-associated microglial phenotype.}

Next, we investigated whether dysfunctional VSMCs can activate microglial cells under AD-like condition. Therefore, we used a trans-well assay to quantify the migratory potential of microglia in response to the inflammatory signals from synthetic VSMCs treated with PDGFBB, Tau ${ }^{\mathrm{P} 301 \mathrm{~L}}$ and LPS. To achieve this goal, we first labelled microglia cells with a membrane binding red fluorophore under normal conditions and in parallel VSMCs were plated under AD-like 
conditions for $72 \mathrm{hr}$ in a 24 trans-well plate followed by incubation with growing media for $16 \mathrm{hr}$. Remarkably, microglial cells migrated significantly towards to VSMCs that were exposed to PDGFBB, mutant TauP301L and LPS (Figure 3A, top panel). Immunofluorescence analysis of pro-inflammatory markers for activated microglia (M1 microglia) such as MHC-II and iNOS demonstrated that under AD-like conditions, VSMCs can induce the activation of microglia potentially through a paracrine communication. Interestingly, confocal analyses revealed CD68 colocalization with SM22 $\alpha$, with evidence of microglia physically interacting with VSMCs under AD-like conditions, analogous to previously reported microglia-neuron interactions in the brain (Pósfai et al., 2019) (Figure 3A, middle panel). In contrast, pre-treatment of microglia cells with all three AD-like conditions failed to promote the migration of healthy VSMCs (Figure 3A, Lower panel). Immunostaining showed increased levels of MMP9 and PDGFR- $\beta$ in VSMCs under ADlike conditions (Figure 3B). However, PDGFBB treatment failed to induce MMP9 expression in microglial cells, supporting the notion of a paracrine VSMC-mediated activation of microglial cells in AD brains (Figure 3B). To support this idea, we performed a co-culture experiment by pre-treating healthy VSMCs with PDGFBB, mutant Tau ${ }^{\mathrm{P} 301 \mathrm{~L}}$ and LPS for $72 \mathrm{hr}$ followed by coculture with healthy microglia cells in normal conditions. Indeed, VSMCs pre-treated with PDGFBB and TauP301L induced expression of the classic M1 microglial marker, MHC-II but, LPS-treated VSMCs failed to activate microglia (Figure 3C). Then we performed a second experiment using the supernatant of VSMCs pre-treated with all 3 AD-like conditions to incubate healthy microglia cells for 48hrs. Immunofluorescence analysis showed that supernatants from VSMCs treated with PDGFBB and Tau ${ }^{\mathrm{P} 301 \mathrm{~L}}$ was sufficient to promoted morphologic and phenotypic changes corresponding to activated microglia associated with brain neuroinflammation in AD patients (Figure 3D) (Leng at al., 2020)al. Collectively, our results suggest that dysfunctional VSMCs can activate microglia to drive brain neuroinflammation.

\section{In silico analysis of mutant Tau proteins and in vitro and in vivo Tau hyperphosphorylation status}

To better understand the molecular and structural impact of mutations in the Tau protein associated with neurodegenerative diseases, we performed an in-silico study using molecular dynamics simulations (MDS) (Table S1). By using the Tau full-length 2N4R sequences (441 aa), we built the 3D structure of the protein (Figures S2A and S2B. Movie S1). Then based on this $3 \mathrm{D}$ model, the $\mathrm{Tau}^{\mathrm{P} 301 \mathrm{~S}}$ and $\mathrm{Tau}^{\mathrm{P} 301 \mathrm{~L}}$ were built performing 301 site direct mutagenesis using UCSF Chimera software (Pettersen et al., 2004), allowing local structural relaxion to avoid steric residue clashes (Figure 4A and S2C). Tau proteins are considered intrinsically disordered, there is evidence that in solution, they can adopt multiple globular structures (Popov et al., 2019). Thus, we sought to analyze all three Tau proteins with 500 ns of MDS to stabilize the physical motions of atoms in the Tau proteins and thus mimic physiological conditions. Importantly the residue 301 is located at the microtubule binding repeats domains R2 and R3 (MTBRs) where the assembly and stabilization of axonal connections occurs at the 
neuronal cell body (Figure S3B). Even though all three proteins fold towards a globular structure, the folding was remarkably different for the Tau protein with a proline to leucine substitution compared to the proline to serine substitution, in terms of folding patterns. While looking at the global surface of the Tau ${ }^{\mathrm{P} 301 \mathrm{~L}}$, we observed a decrease in the solvent-accessible surface area (SASA) from $360 \mathrm{~nm}^{2}$ to $240.31 \mathrm{~nm}^{2}$. The MTBR domain showed a significant increase in the SASA (7\%), potentially exposing a greater area of interaction thus creating a predisposition to posttranslational modification including phosphorylation of multiple residues (Table S2). Another important consequence of the proline to leucine substitution was observed on the electrostatic potential (ESP) surfaces at the MTBRs. All three proteins show nucleophilic and hydrophobic interactions. However, the R2-R3 domains of the Tau ${ }^{\mathrm{P} 301 \mathrm{~L}}$ adopt an additional negative electrostatic pattern creating a more promiscuous Tau protein which may be more prone to interact with multiple Tau-protein kinases, ligands, and drugs (Figure S4A-S4C). To achieve these conformational changes the proline to leucine substitution induces loss of residue contacts at H299, V300, G303, G304, S305, V309, L325 and creates uncommon interactions with residues at Q307, K321 and N-terminal regions (Figures 4A, 4B, S3A and S3C-S3E). Remarkably, the misfolding of the Tau ${ }^{\mathrm{P} 301 \mathrm{~L}}$ protein reduced the distance of the $\mathrm{Y} 18$ residue toward to the MTBRs right where the P301L substitution occurs (Figure 4C and S5E). In this context the $S 262$ residue showed the largest area of exposure to the solvent and thereby augmenting its capability to interact with Tau-protein kinases (Figure S6A). Similarly, multiple Tau residues previously associated with brain neurodegeneration were relocated at the proximity of the proline to leucine substitution and augmenting their ability to posttranslational modifications (Figure 4B and Movie S2). In agreement with our in silico results, we observed that VSMCs under AD-like conditions produced high levels of total and phosphorylated Tau. Indeed, VSMCs treated with PDGFBB and Tau ${ }^{\mathrm{P} 301 \mathrm{~L}}$ promoted predominately the hyperphosphorylation of the S262 residue and also other residues at Y18 and T205, which associated with up-regulation of Cofilin-1, a proliferative-VSMC marker (San et al., 2008). Interestingly, Cofilin-1 has recently been implicated in the pathogenesis of AD (Kang et al., 2019), supporting the potentially role of dysfunctional VSMCs in neurotoxicity and the AD progression (Figure 4D and S1A). Immunofluorescence of 3xTg-AD brains at 13 weeks and 22 weeks demonstrated that loss of contractile proteins (Sm22 $\alpha$ and $\alpha$-Sma) in brain arterioles occurs in an age-dependent manner which associated with an increased production of CD68 by VSMCs during the disease state (Figure 4E) Therefore, Tau misfolding is associated with hyperphosphorylation and strongly supports the notion that dysfunctional VSMCs can induce conformational changes in Tau protein and neurotoxicity previously implicated in tauopathies including $A D$. 


\section{DISCUSSION}

Vascular dysfunction is a well-established clinical aspect of $A D$, with subtle changes in microvasculature of the brain manifesting at the onset of clinical symptoms (Govindpani et al., 2019, Arvanitakis et al 2016). However, the precise role of VSMCs in the pathogenesis of AD remains unclear. The neurovascular unit (NVU) is primarily composed of endothelial cells, pericytes, astrocytes and vascular smooth muscle cells (VSMCs) (Zlokovic et al., 2011). Given the inherent phenotypic plasticity of vascular smooth muscle cells, they readily switch from normal contractile to synthetic phenotypes in response to a variety of environmental stimuli, including inflammatory cytokines, genetic mutations or chemical compounds. Previous neuropathological studies of $A D$ autopsies showed that $80 \%$ of $A D$ patients without vascular dementia developed abnormal vascular features, including multiple micro-infarcts, lacunes, cerebral micro-bleeds indicative of intracranial atherosclerosis, perivascular spacing and cerebral amyloid angiopathy (CAA) (Toledo et al., 2013). Together these observations support the concept that cerebrovascular dysfunction is a prominent pathological feature of $A D$, and that the neurovascular unit is a central catalyst of $A D$ initiation and progression.

Our findings point towards the contribution of dysfunctional VSMCs in the development of neuroinflammation and AD progression. In this study, downregulation of contractile genes critical for the homeostasis of brain arterioles was tightly linked to the production of neuroinflammatory markers such as MMP9, CD68 and IL-6. Moreover, transdifferentiated VSMCs can produce high levels of total and hyperphosphorylated Tau protein. Remarkably under AD-like conditions VSMCs promoted hyperphosphorylation of Tau-T205 which has been associated with early neurological decline in AD patients, further illuminating the contribution of VSMCs in the initiation of clinical symptoms. We found that brain arterioles of 3xTg-AD mice contained high levels of PDGFBB (Platelet-derived growth factor-BB) which is a well-known inducer of VSMC transdifferentiation through a potent mitogenic activity by inhibiting expression of contractile genes such as aSMA (ACTA2), SM22 $\alpha$ (TAGLN), LRP1 and CNN1 (Calponin) (Tallquist et al., 2004; Salabei et al., 2013). Furthermore, MMP proteins known to be associated with other vascular smooth muscle cell related diseases including aortic aneurysm, vascular calcification, and vascular stenosis, was also found elevated in postmortem brain tissue of AD patients. In agreement with our work, elevated MMP proteins in VSMCs under AD-like conditions coincided with downregulation of SM22a, which is known to be a negative regulator of MMP9 (Nair et al., 2006) indicating the negative feedback regulation of neuroinflammatory molecules due to loss of VSMC-contractile phenotype. Similarly, downregulation of LRP1 in VSMCs was observed in AD-like conditions and may impact $A \beta$ clearance leading to $A \beta$ accumulation and plaque formation during diseases (DeSimone et al., 2017; Kanekiyo et al., 2012; Nelson et al., 2017). Along these lines, microglia cells have an increased phagocytic response to $A \beta$ and are known effectors of $A \beta$ clearance in the brain (Lopes et al., 2008; Streit et al., 2009). However, during AD, microglia adopt reactive states characterized by both morphological and functional changes including increased expression of iNOS and MHC-II and other acute inflammatory molecules (Zabel et al., 2013). Our in vitro assays demonstrated the potential of dysfunctional VSMCs to trigger AD-associated microglial 
phenotypes. These changes were more remarkable in PDGFBB and Tau ${ }^{\mathrm{P} 301 \mathrm{~L}}$ conditions, further supporting the contribution of unhealthy VSMC in promoting AD related pathology features and neurodegeneration.

Some forms of genetically triggered neurodegenerative diseases such as Tau ${ }^{\mathrm{P} 301 \mathrm{~L}}$ protein promote neurofibrillary deposits (Kawasaki et al., 2020). Tau hyperphosphorylation may promote self-aggregation and subsequent fibrillization (Eschmann et al., 2017; Berendsen et al., 2000). Our in silico analysis of the 3D structures of wild-type and Tau ${ }^{\text {P301L }}$ proteins demonstrates that changes in the amino acid sequence could have a dramatic impact on the conformational structure and misfolding, leading to the phosphorylation of multiple residues via rearrangement of key amino acids (e.g. Y18, T181, S202, T205, S262 and S356) involved in AD progression. In agreement with our in silico analysis, we found that dysfunctional VSMCs can induce Tau misfolding and promote its hyperphosphorylation. In addition, our in vivo studies reveal that brain arterioles contained significant levels of Tau protein and inflammatory markers co-localizing with VSMCs in 3xTg-AD mice. Additionally, we uncovered that Tau protein levels and inflammatory signal were relative to the age of the 3xTg-AD mouse brain indicating that the vascular tissue may play a pathological role in the development of the disease as early as before the outcome of clinical symptoms.

Overall, this study demonstrates the pivotal role of dysfunctional VSMCs in AD development and progression. It has refined our understanding of the contributory role of the neuro-vascular unit and the direct contribution of VSMC towards Alzheimer disease pathogenesis. While the majority of AD studies have focused on neural and glial cells, this study extends the catalog of promoting factors in AD which promise to enable development of new therapeutic interventions and vascular-related biomarkers for early detection of the disease. In this context, recent studies have showed that targeting the vascular tissue with drugs such as Losartan, ACEi or Captopril could help to improve memory and cognitive decline (Lee et al., 2020; Royea et al., 2020; Royea et al., 2020; Asraf et al., 2018; Rahimi et al., 2020). Therefore, this study supports the idea of VSMCs as a novel therapeutic target in AD. 


\section{REFERENCES}

Abraham MJ, Murtola T, Schulz R, Páll S, Smith JC, Hess B, Lindahl E. GROMACS: High performance molecular simulations through multi-level parallelism from laptops to supercomputers. SoftwareX. 2015 Sep. 1, 19-25. doi: 10.1016/j.softx.2015.06.001.

Adolfsson, O., Pihlgren M, Toni N, Varisco Y, Buccarello AL, Antoniello K, Lohmann S, Piorkowska K, Gafner V, Atwal JK, Maloney J, Chen M, Gogineni A, Weimer RM, Mortensen DL, Friesenhahn M, Ho C, Paul R, Pfeifer A, Muhs A, Watts RJ. An Effector-Reduced AntibetaAmyloid (Abeta) Antibody with Unique Abeta Binding Properties Promotes Neuroprotection and Glial Engulfment of Abeta. J Neurosci. 2012; 32(28):9677-89.

Agarwal P, Morris MC, Barnes LL. Racial Differences in Dietary Relations to Cognitive Decline and Alzheimer's Disease Risk: Do We Know Enough? Front Hum Neurosci. 2020 Sep 3;14:359. doi: 10.3389/fnhum.2020.00359. PMID: 33100990; PMCID: PMC7497764.

Alzheimer's Association (2018). 2018 Alzheimer's disease facts and figures. Alzheimers Dement. 14 367-429. 10.1016/j.jalz.2018.02.001.

Arvanitakis Z, Capuano AW, Leurgans SE, Bennett DA, Schneider JA. Relation of cerebral vessel disease to Alzheimer's disease dementia and cognitive function in elderly people: a crosssectional study. Lancet Neurol 2016;15:934-43. doi:10.1016/S1474-4422(16)30029-1.

Asai H, Ikezu S, Tsunoda S, Medalla M, Luebke J, Haydar T, Wolozin B, Butovsky O, Kügler $\mathrm{S}$, Ikezu T. Depletion of microglia and inhibition of exosome synthesis halt tau propagation. Nat Neurosci. 2015 Nov;18(11):1584-93. doi: 10.1038/nn.4132. Epub 2015 Oct 5. PMID: 26436904; PMCID: PMC4694577

Asraf K, Torika N, Apte RN, Fleisher-Berkovich S. Microglial Activation Is Modulated by Captopril: in Vitro and in Vivo Studies. Front Cell Neurosci. 2018 May 1;12:116. doi: 10.3389/fncel.2018.00116. PMID: 29765306; PMCID: PMC5938337.

Baker NA, Sept D, Joseph S, Holst MJ, McCammon JA. Electrostatics of nanosystems: application to microtubules and the ribosome. PNAS 2001 Aug 28. 98(18), 10037-10041. doi: 10.1073/pnas.181342398.

Barbier P, Zejneli O, Martinho M, Lasorsa A, Belle V, Smet-Nocca C, Tsvetkov PO, Devred F, Landrieu I. Role of Tau as a Microtubule-Associated Protein: Structural and Functional Aspects. Front Aging Neurosci. 2019 Aug 7;11:204.

Barthélemy NR, Li Y, Joseph-Mathurin N, Gordon BA, Hassenstab J, Benzinger TLS, Buckles V, Fagan AM, Perrin RJ, Goate AM, Morris JC, Karch CM, Xiong C, Allegri R, Mendez PC, Berman SB, Ikeuchi T, Mori H, Shimada H, Shoji M, Suzuki K, Noble J, Farlow M, Chhatwal J, Graff-Radford NR, Salloway S, Schofield PR, Masters CL, Martins RN, O'Connor A, Fox NC, Levin J, Jucker M, Gabelle A, Lehmann S, Sato C, Bateman RJ, McDade E; Dominantly Inherited Alzheimer Network. A soluble phosphorylated tau signature links tau, amyloid and 
the evolution of stages of dominantly inherited Alzheimer's disease. Nat Med. 2020 Mar;26(3):398-407. doi: 10.1038/s41591-020-0781-z. Epub 2020 Mar 11. PMID: 32161412; PMCID: PMC7309367.

Barthélemy NR, Mallipeddi N, Moiseyev P, Sato C, Bateman RJ. Tau Phosphorylation Rates Measured by Mass Spectrometry Differ in the Intracellular Brain vs. Extracellular Cerebrospinal Fluid Compartments and Are Differentially Affected by Alzheimer's Disease. Front Aging Neurosci. 2019 May 21;11:121.

Beazely MA, Lim A, Li H, Trepanier C, Chen X, Sidhu B, Macdonald JF. Platelet-derived growth factor selectively inhibits NR2B-containing N-methyl-D-aspartate receptors in CA1 hippocampal neurons. J Biol Chem. 2009; 284(12):8054-8063.

Bell RD, Deane R, Chow N, Long X, Sagare A, Singh I, Streb JW, Guo H, Rubio A, Van Nostrand W, Miano JM, Zlokovic BV.SRF and myocardin regulate LRP-mediated amyloidbeta clearance in brain vascular cells. Nat Cell Biol. 2009 Feb;11(2):143-53.

Bennett DA, Yu L, De Jager PL. Building a pipeline to discover and validate novel therapeutic targets and lead compounds for Alzheimer's disease. Biochem Pharmacol. 2014 Apr 15;88(4):617-30. doi: 10.1016/j.bcp.2014.01.037. Epub 2014 Feb 6. PMID: 24508835; PMCID: PMC4054869.

Berendsen, $\mathrm{H}$, Hayward, S. Collective protein dynamics in relation to function. Curr Opin Struct Biol. 2000 Apr;10(2):165-9. doi: 10.1016/s0959-440x(00)00061-0.

Berendsen HJ, Postma JV, van Gunsteren WF, DiNola ARHJ, Haak JR. Molecular dynamics with coupling to an external bath. J. Chem. Phys. 1984 Jun. 81(8), 3684-3690. doi: 10.1063/1.448118.

Brown SP, Muchmore SW. Large-scale application of high-throughput molecular mechanics with Poisson- Boltzmann surface area for routine physics-based scoring of protein- ligand complexes. J. Med. Chem. 2009 Apr 22. 52(10), 3159-3165. doi: 10.1021/jm801444x.

Bussi G, Donadio D, Parrinello M. Canonical sampling through velocity rescaling. J. Chem. Phys. 2007 Jan 3. 126(1), 014101. doi: 10.1063/1.2408420.

Castro PR, Barbosa AS, Pereira JM, Ranfley H, Felipetto M, Gonçalves CAX, Paiva IR, Berg BB, Barcelos LS. Cellular and Molecular Heterogeneity Associated with Vessel Formation Processes. Biomed Res Int. 2018 Oct 10;2018:6740408. doi: 10.1155/2018/6740408. PMID: 30406137; PMCID: PMC6199857.

Chan KY, Wang W, Wu JJ, Liu L, Theodoratou E, Car J, Middleton L, Russ TC, Deary IJ, Campbell H, Wang W, Rudan I; Global Health Epidemiology Reference Group (GHERG). Epidemiology of Alzheimer's disease and other forms of dementia in China, 1990-2010: a systematic review and analysis. Lancet. 2013;381:2016-2023. doi: 10.1016/S01406736(13)60221-4 
Chao J, Yang L, Yao H, Buch S. Platelet-derived growth factor-BB restores HIV Tat -mediated impairment of neurogenesis: role of GSK-3beta/beta-catenin. J Neuroimmune Pharmacol. 2014; 9(2):259-268.

Chen D, Drombosky KW, Hou Z, Sari L, Kashmer OM, Ryder BD, Perez VA, Woodard DR, Lin MM, Diamond MI, Joachimiak LA. Tau local structure shields an amyloid-forming motif and controls aggregation propensity. Nat Commun. 2019 Jun 7;10(1):2493. doi: 10.1038/s41467019-10355-1.

Chow N, Bell RD, Deane R, Streb JW, Chen J, Brooks A, Van Nostrand W, Miano JM, Zlokovic BV. Serum response factor and myocardin mediate arterial hypercontractility and cerebral blood flow dysregulation in Alzheimer's phenotype. Proc Natl Acad Sci U S A. 2007 Jan 16;104(3):823-8.

Claesson-Welsh L. Mechanism of action of platelet-derived growth factor. Int J Biochem Cell Biol. 1996 Apr;28(4):373-85. doi: 10.1016/1357-2725(95)00156-5. PMID: 9026349.

De la Torre J. The Vascular Hypothesis of Alzheimer's Disease: A Key to Preclinical Prediction of Dementia Using Neuroimaging. J Alzheimers Dis. 2018;63(1):35-52. doi: 10.3233/JAD180004. PMID: 29614675.

Deaton RA, Gan Q, Owens GK. Sp1-dependent activation of KLF4 is required for PDGF BBinduced phenotypic modulation of smooth muscle. Am J Physiol Heart Circ Physiol. 2009; 296 : H1027-37

DeSimone CV, Graff-Radford J, El-Harasis MA, Rabinstein AA, Asirvatham SJ, Holmes DR Jr. Cerebral Amyloid Angiopathy: Diagnosis, Clinical Implications, and Management Strategies in Atrial Fibrillation. J Am Coll Cardiol. 2017 Aug 29;70(9):1173-1182.

Dolinsky TJ, Nielsen JE, McCammon JA, Baker NA. PDB2PQR: an automated pipeline for the setup of Poisson-Boltzmann electrostatics calculations. Nucleic Acids Res. 2004 Jul 1. 32(suppl_2), W665-W667.doi: 10.1093/nar/gkh381.

Dumanchin C, Camuzat A, Campion D, Verpillat P, Hannequin D, Dubois B, Saugier-Veber P, Martin C, Penet C, Charbonnier F, Agid Y, Frebourg T, Brice A. Segregation of a missense mutation in the microtubule-associated protein tau gene with familial fronto-temporal dementia and parkinsonism. Hum Mol Genet. 1998 Oct;7(11):1825-9.

Egawa-Tsuzuki T, Ohno M, Tanaka N, Takeuchi Y, Uramoto H, Faigle R, Funa K, Ishii Y, Sasahara M. The PDGF B-chain is involved in the ontogenic susceptibility of the developing rat brain to NMDA toxicity. Exp Neurol. 2004; 186(1):89-98.

Ercan-Herbst E, Ehrig J, Schöndorf DC, Behrendt A, Klaus B, Gomez Ramos B, Prat Oriol N, Weber C, Ehrnhoefer DE. A post-translational modification signature defines changes in soluble tau correlating with oligomerization in early stage Alzheimer's disease brain. Acta Neuropathol Commun. 2019 Dec 3;7(1):192. doi: 10.1186/s40478-019-0823-2. 
Erkinjuntti, T.; Román, G.; Gauthier, S.; Feldman, H.; Rockwood, K. Emerging therapies for vascular dementia and vascular cognitive impairment. Stroke 2004, 35, 1010-1017.

Eschmann NA, Georgieva ER, Ganguly P, Borbat PP, Rappaport MD, Akdogan Y, Freed JH, Shea JE, Han S. Signature of an aggregation-prone conformation of tau. Sci Rep. 2017 Mar 17;7:44739. doi: 10.1038/srep44739.

Ewald, PP. Die Berechnung optischer und elektrostatischer Gitterpotentiale. Annalen der physik. 1921 Aug 07. 369(3), 253-287. doi: 10.1002/andp.19213690304.

Frackowiak J, Wisniewski HM, Wegiel J, Merz GS, Iqbal K, Wang KC. Ultrastructure of the microglia that phagocytose amyloid and the microglia that produce beta-amyloid fibrils. Acta Neuropathol. 1992; 84(3):225-233. [PubMed: 1414275]

Frismantiene A, Philippova M, Erne P, Resink TJ. Smooth muscle cell-driven vascular diseases and molecular mechanisms of VSMC plasticity. Cell Signal. 2018 Dec;52:48-64. doi: 10.1016/j.cellsig.2018.08.019.

Gianni D, Zambrano N, Bimonte M, Minopoli G, Mercken L, Talamo F, Scaloni A, Russo T.Platelet-derived growth factor induces the beta-gamma-secretase-mediated cleavage of Alzheimer's amyloid precursor protein through a Src-Rac-dependent pathway. J Biol Chem. 2003 Mar 14;278(11):9290-7.

Giménez-Llort L, Arranz L, Maté I, De la Fuente M. Gender-specific neuroimmunoendocrine aging in a triple-transgenic 3xTg-AD mouse model for Alzheimer's disease and its relation with longevity. Neuroimmunomodulation. 2008;15(4-6):331-43. doi: 10.1159/000156475. Epub 2008 Nov 26. PMID: 19047809.

Govindpani K, McNamara LG, Smith NR, Vinnakota C, Waldvogel HJ, Faull RL, Kwakowsky A (2019) Vascular dysfunction in Alzheimer's disease: A prelude to the pathological process or a consequence of it? J Clin Med doi: 10.3390/jcm8050651.

Govindpani, K., Vinnakota, C., Waldvogel, H. J., Faull, R. L., and Kwakowsky, A. (2020). Vascular dysfunction in Alzheimer's disease: a biomarker of disease progression and a potential therapeutic target. Neural Regen. Res. 15,1030-1032. doi: 10.4103/16735374.270306

Guo DC, Regalado ES, Pinard A, Chen J, Lee K, Rigelsky C, Zilberberg L, Hostetler EM, Aldred M, Wallace SE, Prakash SK; University of Washington Center for Mendelian Genomics, Leal SM, Bamshad MJ, Nickerson DA, Natowicz M, Rifkin DB, Milewicz DM. LTBP3 Pathogenic Variants Predispose Individuals to Thoracic Aortic Aneurysms and Dissections. Am J Hum Genet. 2018 Apr 5;102(4):706-712. doi: 10.1016/j.ajhg.2018.03.002. PMID: 29625025; PMCID: PMC5985335.

Hansen, D.V.; Hanson, J.E.; Sheng, M. Microglia in Alzheimer's disease. J. Cell Biol. 2018, 217, 459-472. 
Hess B. P-LINCS: A parallel linear constraint solver for molecular simulation. J. Chem. Theory Comput. 2008 Dec 1. 4(1), 116-122. doi: 10.1021/ct700200b.

Hockney RW, Goel SP, Eastwood JW. Quiet high-resolution computer models of a plasma. J. Comput. Phys. 1974 Feb. 14(2), 148-158. doi: 10.1016/0021-9991(74)90010-2.

Humphrey W, Dalke A, Schulten K. VMD: visual molecular dynamics. J. Molec. Graphics. 1996 Feb. 14(1), 33-38. doi: 10.1016/0263-7855(96)00018-5.

Hutton M, Lendon CL, Rizzu P, Baker M, Froelich S, Houlden H, Pickering-Brown S, Chakraverty S, Isaacs A, Grover A, Hackett J, Adamson J, Lincoln S, Dickson D, Davies P, Petersen RC, Stevens M, de Graaff E, Wauters E, van Baren J, Hillebrand M, Joosse M, Kwon JM, Nowotny P, Che LK, Norton J, Morris JC, Reed LA, Trojanowski J, Basun H, Lannfelt L, Neystat M, Fahn S, Dark F, Tannenberg T, Dodd PR, Hayward N, Kwok JB, Schofield PR, Andreadis A, Snowden J, Craufurd D, Neary D, Owen F, Oostra BA, Hardy J, Goate A, van Swieten J, Mann D, Lynch T, Heutink P. Association of missense and 5'-splice-site mutations in tau with the inherited dementia FTDP-17. Nature. 1998; 393:702-705. [PubMed: 9641683]

Ibrahim YM, Garimella SV, Prost SA, Wojcik R, Norheim RV, Baker ES, Rusyn I, Smith RD. Development of an Ion Mobility Spectrometry-Orbitrap Mass Spectrometer Platform. Anal Chem. 2016 Dec 20;88(24):12152-12160. doi: 10.1021/acs.analchem.6b03027. Epub 2016 Dec 1. PMID: $28193022 ;$ PMCID: PMC6211177.

Iqbal, K., Alonso, A. del C., Chen, S., Chohan, M. O., El-Akkad, E.,Gong, C. X., et al. (2005). Tau pathology in Alzheimer disease and other tauopathies. Biochim. Biophys. Acta 1739, 198-210. doi: 10.1016/j.bbadis.2004.09.008

Isselbacher EM, Lino Cardenas CL, Lindsay ME. Hereditary Influence in Thoracic Aortic Aneurysm and Dissection. Circulation. 2016 Jun 14;133(24):2516-28. doi: 10.1161/CIRCULATIONAHA.116.009762. PMID: 27297344; PMCID: PMC5031368.

Janelidze S, Berron D, Smith R, Strandberg O, Proctor NK, Dage JL, Stomrud E, Palmqvist S, Mattsson-Carlgren N, Hansson O. Associations of Plasma Phospho-Tau217 Levels With Tau Positron Emission Tomography in Early Alzheimer Disease. JAMA Neurol. 2020 Nov 9:e204201.

Jhoo JH, Kim KW, Huh Y, Lee SB, Park JH, Lee JJ, Choi EA, Han C, Choo IH, Youn JC, Lee DY, Woo Jl. Prevalence of dementia and its subtypes in an elderly urban Korean population: results from the Korean Longitudinal Study on Health And Aging (KLoSHA). Dement Geriatr Cogn Disord. 2008;26:270-276. doi: 10.1159/000160960

Jorgensen WL, Madura JD. Temperature and size dependence for Monte Carlo simulations of TIP4P water. Mol. Phys. 1985 Sep 9. 56(6), 1381-1392. doi: 10.1080/00268978500103111. 
Jorgensen WL, Maxwell DS, Tirado-Rives J. Development and testing of the OPLS all-atom force field on conformational energetics and properties of organic liquids. J. Am. Chem. Soc. 1996 Nov 13. 118(45), 11225-11236. doi: 10.1021/ja9621760.

Kalaria RN, Maestre GE, Arizaga R, Friedland RP, Galasko D, Hall K, Luchsinger JA, Ogunniyi A, Perry EK, Potocnik F, Prince M, Stewart R, Wimo A, Zhang ZX, Antuono P; World Federation of Neurology Dementia Research Group. Alzheimer's disease and vascular dementia in developing countries: prevalence, management, and risk factors. Lancet Neurol. 2008;7:812-826.

Kalaria, R.N. Comparison between Alzheimer's disease and vascular dementia: Implications for treatment. Neurol. Res. 2003, 25, 661-664.

Kanekiyo T, Liu CC, Shinohara M, Li J, Bu G. LRP1 in brain vascular smooth muscle cells mediates local clearance of Alzheimer's amyloid- $\beta$. J Neurosci. 2012 Nov 14;32(46):1645865. doi: 10.1523/JNEUROSCI.3987-12.2012.

Kang DE, Woo JA. Cofilin, a Master Node Regulating Cytoskeletal Pathogenesis in Alzheimer's Disease. J Alzheimers Dis. 2019;72(s1):S131-S144. doi: 10.3233/JAD-190585. PMID: 31594228; PMCID: PMC6971827.

Kawasaki R, Tate SI. Impact of the Hereditary P301L Mutation on the Correlated Conformational Dynamics of Human Tau Protein Revealed by the Paramagnetic Relaxation Enhancement NMR Experiments. Int J Mol Sci. 2020 May 30;21(11):3920. doi: 10.3390/ijms21113920.

Kendrick J, Cheung AK, Kaufman JS, Greene T, Roberts WL, Smits G, Chonchol M; HOST Investigators. FGF-23 associates with death, cardiovascular events, and initiation of chronic dialysis. J Am Soc Nephrol. 2011 Oct;22(10):1913-22. doi: 10.1681/ASN.2010121224. Epub 2011 Sep 7. PMID: 21903574; PMCID: PMC3187186.

Kessinger CW, Chou EL, Ghoshhajra B, Yeri AS, Das S, Weintraub NL, Malhotra R, Jaffer FA, Lindsay ME. HDAC9 complex inhibition improves smooth muscle-dependent stenotic vascular disease. JCI Insight. 2019 Jan 24;4(2):e124706. doi: 10.1172/jci.insight.124706. Epub ahead of print. PMID: 30674723; PMCID: PMC6413784.

Khandelwal PJ, Dumanis SB, Herman AM, Rebeck GW, Moussa CEH. Wild type and P301L mutant Tau promote neuro-inflammation and a-Synuclein accumulation in lentiviral gene delivery models. Mol Cell Neurosci. 2012 Jan;49(1):44-53.

Kim S, Lee M, Choi YK. The Role of a Neurovascular Signaling Pathway Involving HypoxiaInducible Factor and Notch in the Function of the Central Nervous System. Biomol Ther (Seoul). 2020 Jan 1;28(1):45-57. doi: 10.4062/biomolther.2019.119. PMID: 31484285; PMCID: PMC6939687. 
Kimbrough IF, Robel S, Roberson ED, Sontheimer H. Vascular amyloidosis impairs the gliovascular unit in a mouse model of Alzheimer's disease. Brain. 2015 Dec;138(Pt 12):371633.

Koller EJ, De La Cruz EG, Machula T, Ibanez KR, Lin WL, Williams T, Riffe CJ, Ryu D, Strang KH, Liu X, Janus C, Golde TE, Dickson D, Giasson BI and Chakrabarty P. Combining P301L and S320F tau variants produces a novel accelerated model of tauopathy. Hum Mol Genet. 2019 Oct 1;28(19):3255-3269.

Kowalska A. Postepy Hig Med Dosw. The genetics of dementias. Part 1: Molecular basis of frontotemporal dementia and parkinsonism linked to chromosome 17 (FTDP-17. 2009 Jun 15;63:278-86.PMID: 19535823 Review. Polish.

Krämer A, Green J, Pollard J Jr, Tugendreich S. Causal analysis approaches in Ingenuity Pathway Analysis. Bioinformatics. 2014 Feb 15;30(4):523-30. doi: 10.1093/bioinformatics/btt703. Epub 2013 Dec 13. PMID: 24336805; PMCID: PMC3928520.

Krupinski J, Issa R, Bujny T, Slevin M, Kumar P, Kumar S, Kaluza J. A putative role for plateletderived growth factor in angiogenesis and neuroprotection after ischemic stroke in humans. Stroke. 1997; 28(3):564-573.

Kumari R, Kumar R, Open-Source Drug Discovery Consortium, Lynn A. g_mmpbsa A GROMACS tool for high-throughput MM-PBSA calculations. J. Chem. Inf. Model. 2014 May 21. 54(7), 1951-1962. doi: 10.1021/ci500020m.

Lamar M, Boots EA, Arfanakis K, Barnes LL, Schneider JA. Common Brain Structural Alterations Associated with Cardiovascular Disease Risk Factors and Alzheimer's Dementia: Future Directions and Implications. Neuropsychol Rev. 2020 Oct 3. doi: 10.1007/s11065-02009460-6. Epub ahead of print. PMID: 33011894.

Lathuilière A, Valdés P, Papin S, Cacquevel M, Maclachlan C, Knott GW, Muhs A, Paganetti $P$, Schneider BL. Motifs in the tau protein that control binding to microtubules and aggregation determine pathological effects. Sci Rep. 2017 Oct 19;7(1):13556. doi: 10.1038/s41598-01713786-2.

Lee D, Lee KH, Park H, Kim SH, Jin T, Cho S, Chung JH, Lim S, Park S. The effect of soluble RAGE on inhibition of angiotensin II-mediated atherosclerosis in apolipoprotein $E$ deficient mice. PLoS One. 2013 Aug 1;8(8):e69669. doi: 10.1371/journal.pone.0069669. Retraction in: PLoS One. 2014;9(9):e108684. PMID: 23936343; PMCID: PMC3731311.

Lee SH, Gomes SM, Ghalayini J, Iliadi KG, Boulianne GL. Angiotensin Converting Enzyme Inhibitors and Angiotensin Receptor Blockers Rescue Memory Defects in DrosophilaExpressing Alzheimer's Disease-Related Transgenes Independently of the Canonical Renin Angiotensin System. eNeuro. 2020 Dec 22;7(6):ENEURO.0235-20.2020. doi: 10.1523/ENEURO.0235-20.2020. PMID: 33060184. 
Leng F, Edison P. Neuroinflammation and microglial activation in Alzheimer disease: where do we go from here? Nat Rev Neurol. 2020 Dec 14. doi: 10.1038/s41582-020-00435-y. Epub ahead of print. PMID: 33318676.

Leszek J, Małyszczak K, Janicka B, Kiejna A, Wiak A. Total Tau in Cerebrospinal Fluid Differentiates Alzheimer's Disease From Vascular Dementia. Med Sci Monit. 2003 Nov; 9(11):CR484-8.

Li T, Huang Y, Cai W, Chen X, Men X, Lu T, Wu A, Lu Z. Age-related cerebral small vessel disease and inflammaging. Cell Death Dis. 2020 Oct 30;11(10):932. doi: 10.1038/s41419-02003137-x. PMID: 33127878; PMCID: PMC7603301.

Li Y, Gao S, Han Y, Song L, Kong Y, Jiao Y, Huang S, Du J, Li Y. Variants of Focal Adhesion Scaffold Genes Cause Thoracic Aortic Aneurysm. Circ Res. 2020 Oct 23. doi: 10.1161/CIRCRESAHA.120.317361. Epub ahead of print. PMID: 33092471.

Liu H, Saffi GT, Vasefi MS, Choi Y, Kruk JS, Ahmed N, Gondora N, Mielke J, Leonenko $Z$, Beazely MA. Amyloid- $\beta$ Inhibits PDGF $\beta$ Receptor Activation and Prevents PDGFBBInduced Neuroprotection. Curr Alzheimer Res. 2018;15(7):618-627.

Llorente-Cortés, V., Costales, P., Bernués, J., Camino-Lopez, S. \& Badimon, L. Sterol regulatory element-binding protein-2 negatively regulates low density lipoprotein receptorrelated protein transcription. J. Mol. Biol. 359, 950-960 (2006).

Llorente-Cortés, V., Royo, T., Otero-Viñas, M., Berrozpe, M. \& Badimon, L. Sterol regulatory element binding proteins downregulate LDL receptor-related protein (LRP1) expression and LRP1-mediated aggregated LDL uptake by human macrophages. Cardiovasc. Res. 74, 526536 (2007).

Lobo A, Launer LJ, Fratiglioni L, Andersen K, Di Carlo A, Breteler MM,Copeland JR, Dartigues JF, Jagger C, Martinez-Lage J, Soininen H, Hofman A.Prevalence of dementia and major subtypes in Europe: a collaborative study of population-based cohorts. Neurologic diseases in the elderly research group. Neurology. 2000;54(11 suppl 5):S4-S9.

Lopes KO, Sparks DL, Streit WJ. Microglial dystrophy in the aged and Alzheimer's disease brain is associated with ferritin immunoreactivity. Glia. 2008; 56(10):1048-60. [PubMed: 18442088].

López-González I, Garcia-Esparcia P, Llorens F, Ferrer I. Genetic and Transcriptomic Profiles of Inflammation in Neurodegenerative Diseases: Alzheimer, Parkinson, Creutzfeldt-Jakob and Tauopathies. Int J Mol Sci. 2016 Feb 4;17(2):206. doi: 10.3390/ijms17020206. PMID: 26861289; PMCID: PMC4783939.

Lv P, Zhang F, Yin YJ, Wang YC, Gao M, Xie XL, Zhao LL, Dong LH, Lin YL, Shu YN, Zhang DD, Liu GX, Han M. SM22a inhibits lamellipodium formation and migration via Ras-Arp2/3 
signaling in synthetic VSMCs. Am J Physiol Cell Physiol. 2016 Nov 1;311(5):C758-C767. doi: 10.1152/ajpcell.00033.2016.

Mack CP. Signaling mechanisms that regulate smooth muscle cell differentiation. Arterioscler Thromb Vasc Biol. 2011 Jul;31(7):1495-505. doi: 10.1161/ATVBAHA.110.221135. PMID: 21677292; PMCID: PMC3141215.

Mirbaha H, Chen D, Morazova OA, Ruff KM, Sharma AM, Liu X, Goodarzi M, Pappu RV, Colby DW, Mirzaei H, Joachimiak LA, Diamond MI. Inert and seed-competent tau monomers suggest structural origins of aggregation. Elife. 2018 Jul 10;7:e36584. doi: 10.7554/eLife.36584.

Mok SS, Losic D, Barrow CJ, Turner BJ, Masters CL, Martin LL, Small DH. The beta-amyloid peptide of Alzheimer's disease decreases adhesion of vascular smooth muscle cells to the basement membrane. J Neurochem. 2006 Jan;96(1):53-64. doi: 10.1111/j.14714159.2005.03539.x.

Morishima-Kawashima M. [Molecular analysis of tau deposited in the FTDP-17 brain]. Rinsho Shinkeigaku. 2001 Dec;41(12):1107-10. Japanese. PMID: 12235810.

Muoio V, Persson PB, Sendeski MM. The neurovascular unit - concept review. Acta Physiol (Oxf). 2014 Apr;210(4):790-8. doi: 10.1111/apha.12250.PMID: 24629161

Nair RR, Solway J, Boyd DD. Expression cloning identifies transgelin (SM22) as a novel repressor of 92-kDa type IV collagenase (MMP-9) expression. J Biol Chem. 2006 Sep 8;281(36):26424-36. doi: 10.1074/jbc.M602703200. Epub 2006 Jul 10. PMID: 16835221.

Navarro, V.; Sanchez-Mejias, E.; Jimenez, S.; Muñoz-Castro, C.; Sanchez-Varo, R.; Davila, J.C.; Vizuete, M.; Gutierrez, A.; Vitorica, J. Microglia in Alzheimer's disease: Activated, dysfunctional or degenerative. Front. Aging Neurosci. 2018, 10, 140.

Neddens J, Temmel M, Flunkert S, Kerschbaumer B, Hoeller C, Loeffler T, Niederkofler V, Daum G, Attems J, Hutter-Paier B. Phosphorylation of different tau sites during progression of Alzheimer's disease. Acta Neuropathol Commun. 2018 Jun 29;6(1):52. doi: 10.1186/s40478-018-0557-6.

Nelson AR, Sagare AP, Zlokovic BV. Role of cluster in the brain vascular clearance of amyloid- $\beta$. Proc Natl Acad Sci U S A. 2017 Aug 15;114(33):8681-8682.

Nirzhor SSR, Khan RI, Neelotpol S. The Biology of Glial Cells and Their Complex Roles in Alzheimer's Disease: New Opportunities in Therapy. Biomolecules. 2018 Sep 10;8(3):93. doi: 10.3390/biom8030093.

Noble W, Hanger DP, Miller CCJ, Lovestone S. The importance of tau phosphorylation for neurodegenerative diseases. Front Neurol. 2013 Jul 1;4:83. 
Oddo S, Caccamo A, Shepherd JD, Murphy MP, Golde TE, Kayed R, Metherate R, Mattson MP, Akbari Y, LaFerla FM. Triple-transgenic model of Alzheimer's disease with plaques and tangles: intracellular Abeta and synaptic dysfunction. Neuron. 2003 Jul 31;39(3):409-21. doi: 10.1016/s0896-6273(03)00434-3. PMID: 12895417.

Owens GK, Kumar MS, Wamhoff BR. Molecular regulation of vascular smooth muscle cell differentiation in development and disease. Physiol Rev. 2004 Jul;84(3):767-801. doi: 10.1152/physrev.00041.2003. PMID: 15269336.

Owens GK. Regulation of differentiation of vascular smooth muscle cells. Physiol Rev. 1995 Jul;75(3):487-517. doi: 10.1152/physrev.1995.75.3.487. PMID: 7624392.

Perlmutter LS, Barron E, Chui HC. Morphologic association between microglia and senile plaque amyloid in Alzheimer's disease. Neurosci Lett. 1990; 119(1):32-36. [PubMed: 2097581]

Pettersen EF, Goddard TD, Huang CC, Couch GS, Greenblatt DM, Meng EC, Ferrin TE. UCSF Chimera-a visualization system for exploratory research and analysis. J. Comput. Chem. 2004 Jul 1. 25(13), 1605-1612. doi: 10.1002/jcc.20084.

Popov KI, Makepeace KA, Petrotchenko EV, Dokholyan NV, Borchers CH. Insight into the structure of the "unstructured" tau protein. Structure 2019 Nov 5. 27(11), 1710-1715.e4. doi: 10.1016/j.str.2019.09.003.

Pósfai B, Cserép C, Orsolits B, Dénes Á. New Insights into Microglia-Neuron Interactions: A Neuron's Perspective.Neuroscience. 2019 May 1;405:103-117. doi: 10.1016/j.neuroscience.2018.04.046.

Qiu C. Epidemiology of Alzheimer's disease: occurrence, determinants, and strategies toward intervention. Dialogues Clin Neurosci. 2009 Jun; 11(2): 111-128.

Rahimi R, Nikfar S, Sadeghi M, Abdollahi M, Moghaddam RH, Farzaei MH. Effect of antihypertensive drugs on cognition and behavioral symptoms of patients with Alzheimer's disease: A meta-analysis. Curr Pharm Biotechnol. 2020 Dec 10. doi: 10.2174/1386207323666201211101720. Epub ahead of print. PMID: 33308129.

Rastelli G, Rio AD, Degliesposti G, Sgobba M. Fast and accurate predictions of binding free energies using MM-PBSA and MM-GBSA. J. Comput. Chem. 2010 Jun 30. 31(4), 797-810. doi: 10.1002/jcc.21372.

Rizzi L, Rosset I, Roriz-Cruz M. Global epidemiology of dementia:Alzheimer's and vascular types. Biomed Res Int. 2014;2014:908915. doi:10.1155/2014/908915

Rong JX, Shapiro M, Trogan E, Fisher EA. Transdifferentiation of mouse aortic smooth muscle cells to a macrophage-like state after cholesterol loading. Proc Natl Acad Sci U S A. 2003 Nov 11;100(23):13531-6. 
Roy A, Kucukural A, Zhang Y. I-TASSER: a unified platform for automated protein structure and function prediction. Nat. Protoc. 2010 Mar 25. 5(4), 725-738. doi: 10.1038/nprot.2010.5.

Royea J, Lacalle-Aurioles M, Trigiani LJ, Fermigier A, Hamel E. AT2R's (Angiotensin II Type 2 Receptor's) Role in Cognitive and Cerebrovascular Deficits in a Mouse Model of Alzheimer Disease. Hypertension. 2020 Jun;75(6):1464-1474. doi: 10.1161/HYPERTENSIONAHA.119.14431. Epub 2020 May 4. PMID: 32362228.

Sakata M, Yanamoto H, Hashimoto N, lihara K, Tsukahara T, Taniguchi T, Kikuchi H. Induction of infarct tolerance by platelet-derived growth factor against reversible focal ischemia. Brain Res.1998; 784(1-2):250-255.

Salabei JK, Cummins TD, Singh M, Jones SP, Bhatnagar A, Hill BG. PDGF-mediated autophagy regulates vascular smooth muscle cell phenotype and resistance to oxidative stress Biochem J. 2013 May 1;451(3):375-88.

San Martín A, Lee MY, Williams HC, Mizuno K, Lassègue B, Griendling KK. Dual regulation of cofilin activity by LIM kinase and Slingshot-1L phosphatase controls platelet-derived growth factor-induced migration of human aortic smooth muscle cells. Circ Res. 2008 Feb 29;102(4):432-8. doi: 10.1161/CIRCRESAHA.107.158923. Epub 2007 Dec 20. PMID: 18096821.

Sen T, Saha $P$, Jiang $T$, Sen N. Sulfhydration of AKT triggers Tau-phosphorylation by activating glycogen synthase kinase $3 \beta$ in Alzheimer's disease. Proc Natl Acad Sci U S A. 2020 Feb 25;117(8):4418-4427. doi: 10.1073/pnas.1916895117. Epub 2020 Feb 12. PMID: 32051249; PMCID: PMC7049105.

Spillantini MG, Crowther R A, Kamphorst W, Heutink P, van Swieten J C. Tau pathology in two Dutch families with mutations in the microtubule-binding region of tau. Am J Pathol. 1998 Nov;153(5):1359-63.

Steinbach SK, Husain M. Vascular smooth muscle cell differentiation from human stem/progenitor cells. Methods. 2016 May 15;101:85-92. doi: 10.1016/j.ymeth.2015.12.004. Epub 2015 Dec 8. PMID: 26678794.

Streit WJ, Braak H, Xue QS, Bechmann I. Dystrophic (senescent) rather than activated microglial cells are associated with tau pathology and likely precede neurodegeneration in Alzheimer's disease. Acta Neuropathol. 2009; 118(4):475-85. [PubMed: 19513731]

Sweeney MD, Montagne A, Sagare AP, Nation DA, Schneider LS, Chui HC, Harrington MG, Pa J, Law M, Wang DJJ, Jacobs RE, Doubal FN, Ramirez J, Black SE, Nedergaard M, Benveniste H, Dichgans M, ladecola C, Love S, Bath PM, Markus HS, Salman RA, Allan SM, Quinn TJ, Kalaria RN, Werring DJ, Carare RO, Touyz RM, Williams SCR, Moskowitz MA, Katusic ZS, Lutz SE, Lazarov O, Minshall RD, Rehman J, Davis TP, Wellington CL, González HM, Yuan C, Lockhart SN, Hughes TM, Chen CLH, Sachdev P, O'Brien JT, Skoog I, Pantoni 
L, Gustafson DR, Biessels GJ, Wallin A, Smith EE, Mok V, Wong A, Passmore P, Barkof F, Muller M, Breteler MMB, Román GC, Hamel E, Seshadri S, Gottesman RF, van Buchem MA, Arvanitakis Z, Schneider JA, Drewes LR, Hachinski V, Finch CE, Toga AW, Wardlaw JM, Zlokovic BV. Vascular dysfunction-The disregarded partner of Alzheimer's disease. Alzheimers Dement. 2019 Jan;15(1):158-167. doi: 10.1016/j.jalz.2018.07.222.

Tallquist M, Kazlauskas A. PDGF signaling in cells and mice. Cytokine Growth Factor Rev. 2004; 15: 205-13.

Toledo JB, Arnold SE, Raible K, Brettschneider J, Xie SX, Grossman M, et al. Contribution of cerebrovascular disease in autopsy confirmed neurodegenerative disease cases in the National Alzheimer's Coordinating Centre. Brain J Neurol 2013;136:2697-706. doi:10.1093/brain/awt188.

Tremblay MA, Acker CM,Davies P. Tau phosphorylated at tyrosine 394 is found in Alzheimer's disease tangles and can be a product of the Abl-related kinase, Arg. Journal of Alzheimer's Disease : JAD, 31 Dec 2009, 19(2):721-733.

Tseng HC, Dichter MA. Platelet-derived growth factor-BB pretreatment attenuates excitotoxic death in cultured hippocampal neurons. Neurobiol Dis. 2005; 19(1-2):77-83.

Tsuboi Y.Rinsho Shinkeigaku. Clinical, genetic and pathological aspects of frontotemporal dementia and parkinsonism linked to chromosome 17 (FTDP-17). 2004 Nov;44(11):875-8. PMID: 15651319 Review. Japanese.

Turner PJ. XMGRACE, Version 5.1. 19. Center for Coastal and Land-Margin Research, Oregon Graduate Institute of Science and Technology, Beaverton, OR. 2005.

Tyrrell DJ, Goldstein DR. Ageing and atherosclerosis: vascular intrinsic and extrinsic factors and potential role of IL-6. Nat Rev Cardiol. 2021 Jan;18(1):58-68. doi: 10.1038/s41569-0200431-7. Epub 2020 Sep 11. PMID: 32918047 ; PMCID: PMC7484613

Wallace AC, Laskowski RA, Thornton JM. LIGPLOT: a program to generate schematic diagrams of protein-ligand interactions. Protein Eng. Des. Sel. 1995 Feb 1. 8(2), 127-134. doi: 10.1093/protein/8.2.127.

Wang G, Jacquet L, Karamariti E, Xu Q. Origin and differentiation of vascular smooth muscle cells. J Physiol. 2015 Jul 15;593(14):3013-30. doi: 10.1113/JP270033. Epub 2015 Jun 9. PMID: 25952975; PMCID: PMC4532522.

Wang, Y., and Mandelkow, E. (2016). Tau in physiology and pathology. Nat. Rev.Neurosci. 17, 5-21. doi: 10.1038/nrn.2015.1

Wesseling H, Mair W, Kumar M, Schlaffner CN, Tang S, Beerepoot P, Fatou B, Guise AJ, Cheng L, Takeda S, Muntel J, Rotunno MS, Dujardin S, Davies P, Kosik KS, Miller BL, Berretta S, Hedreen JC, Grinberg LT, Seeley WW, Hyman BT, Steen H, Steen JA. Tau 
PTM Profiles Identify Patient Heterogeneity and Stages of Alzheimer's Disease. Cell. 2020 Nov 10;S0092-8674(20)31393-3.

Wolfram Research, Inc., Mathematica, Version 12.1, Champaign, IL. 2020.

Xu D, Zhang Y. Improving the physical realism and structural accuracy of protein models by a two-step atomic-level energy minimization. Biophys. J. 2011 Nov 16. 101(10), 25252534. doi: 10.1016/j.bpj.2011.10.024.

Yang J, Yan R, Roy A, Xu D, Poisson J, Zhang Y. The I-TASSER Suite: protein structure and function prediction. Nat. Methods 2014 Dec 30. 12(1), 7-8. doi: 10.1038/nmeth.3213.

Yang J, Zhang Y. I-TASSER server: new development for protein structure and function predictions. Nucleic Acids Res. 2015 Apr 16. 43(W1), W174-W181. doi: 10.1093/nar/gkv342.

You Y,Perkins A, Cisternas P, Muñoz B, Taylor X, You Y, Garringer HJ, Oblak AL, Atwoo d BK, Vidal R, Lasagna-Reeves CA. Tau as a Mediator of Neurotoxicity Associated to Cerebral Amyloid Angiopathy. Acta Neuropathol Commun. 2019 Feb 26;7(1):26.

Zabel M, Schrag M, Crofton A, Tung S, Beaufond P, Van Ornam J, Dininni A, Vinters HV, Coppola G, Kirsch WM. A shift in microglial $\beta$-amyloid binding in Alzheimer's disease is associated with cerebral amyloid angiopathy. Brain Pathol. 2013 Jul;23(4):390-401. doi: 10.1111/bpa.12005. Epub 2012 Nov 28.

Zhu S, Shala A, Bezginov A, Sljoka A, Audette G, Wilson DJ. Hyperphosphorylation of intrinsically disordered tau protein induces an amyloidogenic shift in its conformational ensemble. PLoS One. 2015 Mar 13;10(3):e0120416. doi: 10.1371/journal.pone.0120416. eCollection 2015.

Zlokovic BV. Neurovascular pathways to neurodegeneration in Alzheimer's disease and other disorders. Nat Rev Neurosci. 2011. 12(12),723-738. 


\section{METHODS AND DETAILS}

\section{Human Alzheimer Disease vascular SMC gene expression analysis}

Bulk RNA-seq based gene expression data were analyzed from the dorsolateral prefrontal cortex (post-mortem) from $n=414$ individuals ( $n=151$ cognitively normal, non-demented controls and $n=263$ AD subjects) in the Religious Orders Study and Rush Memory and Aging Project (ROSMAP) (PMID: 31340147). These data were downloaded from the AMP-AD Knowledge portal on the Synapse platform (Sage Bionetworks) using accession number: syn3388564 (https://doi.org/10.7303/syn3388564). Briefly, differentially expressed genes (DEG) were detected between non-demented controls and AD brains using the limma package, after normalizing the expression values and removing batch effects and adjusting for covariates: age at death, sex, postmortem interval and APOE risk allele status. Genes were ranked by log2 fold change and posterior error probability. DEGs were then intersected with differentiated and modulated vascular SMC marker genes previously identified from single-cell RNA-seq of human coronary artery tissues ( $n=34$ subjects) (PMID: 31359001). These DEGs were also queried in single-nuclei RNA-seq of post-mortem human control and AD brain tissues $(n=24$ subjects), courtesy of Dr. Philip De Jager and Dr. Vilas Menon (unpublished data).

\section{Animals}

All mice were cared under strict compliance with the Partners Institutional Animal Care and Use Committee (IACUC), regulated by the United States Department of Agriculture and the United States Public Health Service. Tagln-cre mice (B6.Cg-Tg(Tagln-cre)1Her/J, \# 017491) and TdTomato mice (B6.129S4-Gt(ROSA)26Sortm1Sor/J, Stock No: 003474 | R26R). were acquired from Jackson laboratories. Fixed brains from 3xTg-AD mice (B6;129-Tg (APPSwe,tauP301L)1Lfa Psen1tm1Mpm/Mmjax, MMRRC Stock No: 34830-JAX ), were acquired from Jackson laboratories.

\section{Cell lines}

Primary human vascular smooth muscle cells from carotids of healthy donors were purchased from Cell Applications Inc. (\#3514-05a). Human microglia were purchased from ScienCell Inc. (\#1900). VSMC identity was assessed by immunofluorescence staining of contractile markers, including SM22 $\alpha$ and CNN1. To preserve cell identity, all experiments were carried out at passages 1-5.

\section{AD-like models}

For Ex- vivo experiments, brains from healthy mice were collected and immediately incubated in normal media (Cell Applications, \#311-500) for $2 \mathrm{hrs}$ at $37 \mathrm{C}$ and $5 \% \mathrm{CO}_{2}$. Then, brains were treated with PDGFBB ( $\mathrm{n}=3,20 \mathrm{ng} / \mathrm{mL}$, Sigma-GF149), recombinant Tau P301L ( $\mathrm{n}=3,20 \mu \mathrm{g} / \mathrm{mL}$, rPeptide-T1014-1) or LPS ( $\mathrm{n}=3,0.8 \mu \mathrm{g} / \mathrm{mL}$, Sigma-L9143) for 48hrs, separately. For in vitro experiments, either VSMCs or microglia cells were treated with PDGFBB $(n=4,15 \mathrm{ng} / \mathrm{mL}$, Sigma-GF149), recombinant Tau P301L $(n=4,10 \mu \mathrm{g} / \mathrm{mL}$, rPeptide-T1014-1) or LPS $(n=4$, 
$0.5 \mu \mathrm{g} / \mathrm{mL}$, Sigma-L9143) for $72 \mathrm{hrs}$, separately. Control brains $(\mathrm{n}=3)$ were treated with DMSO at $0.01 \%$. Cells were supplied with growing media containing all three compounds every $24 \mathrm{hrs}$, separately.

\section{Proteomic analysis}

Approximately $400 \mu \mathrm{g}$ of total proteins were extracted from brains treated with DMSO $(n=3)$, PDGFBB $(n=3)$, recombinant Tau P301L $(n=3)$ or LPS $(n=3)$ using RIPA buffer (ThermoFisher, CA, USA) and supplemented with $1 \times$ of protease inhibitor cocktail (Roche) according to the manufacturer's instruction, on ice for $30 \mathrm{~min}$. The protein concentration was determined by a BCA protein assay kit (Pierce Biothech), and then denatured protein samples were separated by SDS-PAGE followed by Coomassie staining. Then gel bands containing separated proteins were analyzed using an Orbitrap mass spectrometer (Thermo Scientific, CA, USa), as reported previously (Ibrahim et al., 2016). Ingenuity Pathway Analysis (IPA, Ingenuity Systems) software was used to identify potential canonical pathways associated with proteomic changes in brains under AD-like conditions. The predicted activation state and activation Z-score are based on the direction of fold change values for those genes in the input data set for which an experimentally observed causal relationship has been established (Kramer et al., 2013).

\section{Quantitative flow cytometry}

For the ex-vivo brains were homogenized and stained with anti-mouse CD68 (clone FA-110) and anti-mouse IL-6R (clone D7715A7) BioLegend. APC-conjugated anti-Feeder Cells (clone mEF-SK4) was purchased from Miltenyi Biotec. Cells were surface stained by incubation with the relevant antibodies diluted in PBS $+2 \%$ FBS for 20 minutes at room temperature, followed by 2 washes with PBS $2 \%$ FBS. When intracellular staining of signature cytokines was performed, cell suspensions were initially incubated for $3-5$ hours at $37^{\circ} \mathrm{C}$ with RPMI T cell media containing $0.1 \%$ ionomycin (MilliporeSigma, 10634), $0.1 \%$ brefeldin A (BioLegend, 420601), $0.1 \%$ monensin (BioLegend, 420701), and $50 \mathrm{ng} / \mathrm{ml}$ of PMA (MilliporeSigma, P8139). After the incubation, surface staining was performed as indicated above, followed by cell fixation for 20 minutes at room temperature in light-protected storage with Fixation buffer (BD Biosciences, 554655). Upon fixation and being washed with PBS $2 \%$ FBS, cell suspension was permeabilized with 1× wash/permeabilization buffer (BD Biosciences, 554723; diluted in distilled water) and intracellular stained for 20 minutes at room temperature in light-protected storage. Absolute cell numbers were quantified using Precision Count Beads (BioLegend). Flow cytometry data was acquired on a LSRII (39) and analyzed using FlowJo software.

\section{QPCR}

Total RNA was extracted from VSMCs under AD-like conditions using miRNeasy kit (Qiagen) following the manufacturer's protocol. RNA samples were used to hybridize Agilent gene expression microarrays (v2. mRNA microarrays, Agilent). Briefly, $100 \mathrm{ng}$ of total RNA was used as the starting template for cDNA synthesis. This cDNA was used as a template to synthesize 
Cy3-labeled cRNA that was hybridized on $8 \times 60 \mathrm{~K}$ high density SurePrint $\mathrm{G} 3$ gene expression human Agilent microarrays at $65^{\circ} \mathrm{C}$ for $17 \mathrm{~h}$. All arrays were normalized by cyclic-LOESS and significance analysis of microarrays (SAM) was applied for statistical analysis of the differentially expressed genes setting a $5 \%$ false discovery rate as a cutoff of statistical significance. 44 genes were found to be dysregulated in the same direction for both siRNA conditions compared with the control group. Fourteen genes were randomly chosen to be validated by qRT-PCR. RNA samples were used to run qRT-PCR on SYBR green system (Applied Biosystem, Foster city, CA). Results were analyzed by the ddCT method and GAPDH (encoding glyceraldehyde-3-phosphate dehydrogenase) was used as a housekeeping gene. Fold change were calculated by taking the average over all the control samples as the baseline.

\section{Wound healing assay}

Human VSMCs and microglial were seeded into silicone inserts plates with a defined cell-free gap (Ibidi-labware) and transfected $24 \mathrm{hrs}$ with specific stimulation. After $48 \mathrm{~h}$ silicone inserts were removed to generate the initial wound. No antiproliferative agents were added to the media, therefore wound healing in our assay reflects the combined activity of migration and proliferation. The wound healing/closure was evaluated $12 \mathrm{hrs}, 24 \mathrm{hrs}$ and $48 \mathrm{hrs}$ later.

\section{Cell migration and invasion assay}

Briefly, 500,000 VSMCs were seeded on the bottom and treated with PDGFBB $(15 \mathrm{ng} / \mathrm{mL}$, Sigma-GF149), recombinant Tau P301L $(10 \mu \mathrm{g} / \mathrm{mL}$, rPeptide-T1014-1) or LPS $(0.5 \mu \mathrm{g} / \mathrm{mL}$, Sigma-L9143) for $72 \mathrm{hrs}$, separately. And 300,000 microglia were labeled with a cell-permeable dye (ThermoFisher, \#R37601) and seeded on the membrane insert under normal conditions. Then both cell lines (VSMCs-Bottom and microglia-Top) were incubated in normal media for $16 \mathrm{hrs}$. Next the membrane insert was removed and cells in the bottom of the plate were fixed with $4 \%$ formaldehyde for quantification and immunofluorescent staining. 24 transwell plates (pore size, $8 \mu \mathrm{m}$ ) were used according to the manufacturer's instructions (Corning, CLS346448EA).

\section{Immunoblotting}

Nuclear and cytoplasmic protein lysates were prepared using NE-PER Kit (Pierce, Rockford, IL, USA) and supplemented with $1 \times$ of protease inhibitor cocktail (Roche) according to the manufacturer's instruction. For detection of nuclear proteins $20 \mu \mathrm{g}$ of total nuclear extracts were mixed with denaturing buffer ( $1 \times$ Laemmli loading buffer with $10 \%$ of $\beta$-mercaptoethanol) and analyzed by SDS-PAGE/western blot. Separated proteins were transferred onto a nitrocellulose membrane using the iBlot transfer system (Novex, ThermoFisher, USA). For detection of cytoplasmic proteins $15 \mu \mathrm{g}$ of cytoplasmic extracts were mixed with denaturing buffer as described above. In general, primary antibodies were used at concentration of 1:100 
and secondary at concentration of 1:10000, although specific concentrations are listed in Supplementary Data 7.

\section{Computational Details}

\section{System building, structural refinements and molecular dynamic simulations (MDS).}

The 2N4R Tau sequence (441 aa), was used to build the wild-type Tau protein 3D structure using the I-TASSER server (Roy et al., 2010; Yang et al., 2015; Yang and Zhang, 2015). The TauP301S and TauP301L were built based on wild-type 3D model by performing 301 site direct mutagenesis using UCSF Chimera software (Pettersen et al., 2004). Then the structural refinement was carried out to avoid residues overlapping using ModRefiner server (Xu and Zhang, 2011). Classical MD simulations were performed using GROMACS 2020.4 package (Abraham et al., 2015) with the OPLS-AA force field parameters (Jorgensen et al., 1996). All three Tau protein systems were built in a triclinic simulation box considering periodic boundary conditions (PBC) in all directions ( $x, y$, and $z)$ (Table S1). Then, they were solvated using the TIP4P water model (Jorgensen et al., 1985), and $\mathrm{Cl}^{-}$ions were used for neutralization of total charge in the simulation box. Mimicking of physiological conditions was performed by ionic strengthening with the addition of $150 \mathrm{mM} \mathrm{NaCl}$. The distance of the protein surfaces to the edge of the periodic box was set at $1.5 \mathrm{~nm}$. And $1 \mathrm{fs}$ step was applied to calculate the motion equations using the Leap-Frog integrator (Hockney et al., 1974). The temperature for proteins and water-ions in all simulations was set at $309.65 \mathrm{~K}$ using the modified Berendsen thermostat (V-rescale algorithm) (Berendsen et al., 1984) with a coupling constant of $0.1 \mathrm{ps.} \mathrm{Pressure} \mathrm{was}$ maintained at 1bar using the Parrinello-Rahman barostat (Bussi et al., 2007) with a compressibility of $4.5 \times 10^{-5}$ bar $^{-1}$ and a coupling constant of $2.0 \mathrm{ps}$. Particle mesh Ewald method (Ewald, 1921) was applied to long-range electrostatic interactions with a cutoff equal to $1.1 \mathrm{~nm}$ for non-bonded interactions with a tolerance of $1 \times 10^{5}$ for contribution in real space of the Tau 3D structures. The Verlet neighbor searching cutoff scheme was applied with a neighbor-list update frequency of 10 steps (20 fs). Bonds involving hydrogen atoms were constrained using the Linear constraint solver (LINCS) algorithm (Hess, 2008). Energy minimization in all simulations was performed with the steepest descent algorithm for a maximum of 100,000 steps. For the equilibration process, we performed two steps, one step of dynamics (1ns) in the NVT (isothermal-isochoric) ensemble followed by 2 ns of dynamics in the NPT (isothermalisobaric) ensemble. Then the final simulation was performed in the NPT ensemble for 500ns followed by the analysis of the Tau 3D structures and their energy properties.

\section{Structural and energetic analysis of Tau 3D protein structures}

All MD trajectories were corrected, and the Tau 3D structures were recentering in the simulation boxes. RMSD, RMSF, radius of gyrations, $\mathrm{H}$ bonds, residue distances, and solvent accessible surface area analyses were performed using the Gromacs tools and results were plotted using XMGrace software (Turner, 2005). For visualization of Tau 3D structures, we used the UCSF Chimera, VMD software packages (Humphrey et al., 1996). Analysis of atomic interactions and 2D plots were generated using the LigPlot software packages (Wallace et al., 1995). The electrostatic potential (ESP) surfaces were calculated using the APBS (Adaptive Poisson- 
Boltzmann Solver) software, and the PDB2PQR software was used to assign the charges and radii to protein atoms (Baker et al., 2001; Dolinski et al., 2004). FEL maps were generated to visualize the energy associated with the conformational structure of all three Tau proteins during the molecular dynamic simulation. FEL maps were generated using the RMSD and radius of gyration as atomic position variables respect to its average structure. FEL maps were plotted using using gmx sham and figures were built using Wolfram Mathematica 12.1 (Wolfram Research, Inc., 2020).

\section{Calculation of binding free energy}

The Molecular Mechanics Poisson-Boltzmann Surface Area (MM/PBSA) calculation of free energies and energy contribution by individual residues were carried out to analyze the impact of amino-acid substitutions (P301S and P301L) in the R2-R3 domains using the last 50ns of MD trajectories and the g_mmpbsa package (Kumari et al., 2014). Therefore, the interacting energy was calculated using the following equation:

$$
\Delta G_{i n t}=G_{T a u}-\left(G_{1}+G_{2}\right)
$$

Where the terms $G_{1}$ and $G_{2}$ are the free energy of the different sites of the Tau protein, and GTau is the free energy of entire Tau 3D structure. In this context, the free energy of each term was calculated as follow:

$$
G_{x}=E_{M M}+G_{\text {solv }}-T S
$$

where $\mathrm{E}_{\mathrm{MM}}$ is the standard mechanical energy (MM) produced from bonded interactions, electrostatic interactions, and van der Waals interactions. $G_{s o l v}$, is the solvation energy that includes the free energy contributions of the polar and nonpolar terms. In this work, we used the solvent accessible volume (SAV) model to calculate the nonpolar term. The TS term refers the entropic contribution and was not included in this calculation due to the computational costs (Brown et al., 2009; Rastelli et al., 2010; Kumari et al., 2014). Finally, 309 Kelvin (K) of temperature was used as the default parameter in all our calculations.

\section{Statistical analysis}

Results are given as mean \pm SD. Student's test was applied to determine the statistical significance of difference between control and treated groups $\left({ }^{*} p<0.05,{ }^{* *} p<0.01\right.$ and $\left.{ }^{* * *} p<0.001\right)$. For all experiments at least three replicates were performed. Two-way analysis of variance (ANOVA) was used to analyze healing versus time of Figure $2 \mathrm{D}(95 \%$ confidence interval is plotted). P-values represent one-way ANOVA followed by Tukey's honestly significant difference (HSD) post-hoc test. All graphs were produced using GraphPad Prism 8.0. 


\section{LEGENDS}

Figure 1. Dysfunctional VSMCs contribute to brain inflammation and Tau hyperphosphorylation.

(A) Heatmap of differentially expressed VSMC marker genes (differentiated and modulated $S M C)$ in post-mortem brains from non-demented control individuals $(n=151)$ and $A D$ patients $(n=257)$. The scale bar indicates log2 fold change in expression determined from the limma $R$ package.

(B) Immunofluorescence staining of brain tissue from normal $(n=6)$ and 3xTg-AD ( $n=6)$ mice at 22wks old, demonstrates loss of Sm22a (green) and increase in PdgfBB (red) in brain arterioles of the $3 \times \mathrm{Tg}-\mathrm{AD}$ mice.

(C) Immunofluorescence staining demonstrates accumulation of Tau protein (magenta) in brain arterioles (green) in brains of the 3xTg-AD mice.

(D) Immunofluorescence analysis of Tau protein (green) and CD68 (magenta) in brains from healthy mice treated with DMSO $(n=3)$ or PDGFBB $(n=3)$.

(E) Western blot demonstrates increased phosphorylation of the Tau-S262 and total Tau in brains treated with PDGFBB.

(F) Proteomic signature of healthy brains treated with DMSO or PDGFBB.

(G) Ingenuity path analysis (IPA) of biological pathways impacted by proteomic changes in brains treated with PDGFBB vs DMSO.

(H) Generation of brain-VSMCs expressing fluorescent red TdTomato protein in vivo.

(I) Representative histogram showing numbers of $\mathrm{VSMC}^{\text {TdTomanto }}$ from brains treated with PDGFBB $(n=3)$, Tau ${ }^{\text {P301L }}(n=3)$, LPS $(n=3)$ or DMSO $(n=3)$.

(J) Dot plot of healthy brains expressing VSMC ${ }^{\text {TdTomanto }}$ stimulated with PDGFBB, Tau ${ }^{\mathrm{P} 301 \mathrm{~L} \text {, }}$ LPS or DMSO by flow cytometry analysis.

Figure 2. Morphological and phenotypic changes of VSMCs under AD-like conditions in vitro

(A) Immunofluorescence staining of primary human VSMCs from carotid arteries stimulated with PDGFBB, Tau ${ }^{\mathrm{P} 301 \mathrm{~L}}$, LPS or DMSO, demonstrate morphologic changes in the cytoskeleton (F-actin, green, top panel) and increased Tau (red) and MMP9 (green) proteins (lower panel). 
(B) Heatmap of mRNA expression of contractile, synthetic, and inflammatory genes from VSMCs under AD-like conditions versus control group (DMSO). Red indicate upregulated, white indicate no significant change and blue indicate downregulated.

(C) Flow cytometry analysis of CD68 and IL-6R expression in VSMCs under AD-like conditions.

(D) Wound healing assay demonstrate that AD-like conditions favor the proliferative phenotype of VSMCs.

Figure 3. Dysfunctional VSMCs induce AD-associated microglial phenotype.

(A) Representative trans-well migration and invasion assay shows enhanced trans-well migration of microglia towards to VSMCs under AD-like conditions (top panel). In contrast, microglia under AD-like conditions did not promote trans-well migration of healthy VSMCs.

(B) Immunofluorescence staining of PDGFBR- $\beta$ (magenta) and MMP9 (green) in VSMCs and microglia under normal (DMSO) or AD-like conditions.

(C) Representative micrograph of co-culture assay of VSMCs (magenta) stimulated with PDGFBB, Tau ${ }^{\mathrm{P} 301 \mathrm{~L}}$, LPS or DMSO and healthy microglia cells (blue).

(D) Immunofluorescence staining of microglia cells incubated with supernatants from VSMCs stimulated with PDGFBB, Tau ${ }^{\mathrm{P} 301 \mathrm{~L}}$, LPS or DMSO, shows induction of microglia activation assessed by iNOS staining.

Figure 4. In silico analysis of mutant Tau proteins and in vitro and in vivo Tau hyperphosphorylation status

(A) Representative western blot image of levels of t-Tau and multiple phosphorylate Tau residues from total lysates of VSMCs under AD-like conditions

(B-C) in silico analysis of the WT and mutant Tau ${ }^{\mathrm{P} 301 \mathrm{~L}}$.

(D) Immunofluorescence analysis of AD markers, Tau (Magenta), CD68 (yellow) and VSMC marker Sm22a (green) and Acta2 (red) in brain from normal and 3xTg-AD mice at 13wks and 22 wks. 


\section{SUPPLEMENTARY LEGENDS}

\section{Figure S1. Tau protein structures used in this work.}

(A) Circos plot of the full-length Tau protein (2N4R) linear sequence.

(B) Front and top views of the wild-type Tau 3D protein obtained with I-Tasser server.

(C) Close up of the R2-R3 domain and alignment of Tau wild-type (orange color), Tau ${ }^{\mathrm{P} 301 \mathrm{~L}}$ (blue), and Tau ${ }^{\mathrm{P} 301 \mathrm{~S}}$ (green).

Figure S2. Effects of the $\mathbf{3 0 1}$ amino-acid substitution on the structural energy.

(A) Plot of energy interaction of the residue 301

(B) Circular heat map of the vibrational frequencies and the $\beta$-factor. Red color indicates highest vibration and energy, green color indicates lowest fluctuation areas and yellow indicates moderate vibration and energy. The upper lines indicate vibrational frequencies of Tau wild-type (orange), TauP301S (green) and TauP301L (blue). The inner lines indicate interactions of the phosphorylated residues with their neighboring residues after 500ns of MD simulations.

(C, D, E) MM/PBSA calculation of interacting environments for the Tau wild-type (orange), $\mathrm{Tau}^{\mathrm{P} 301 \mathrm{~S}}$ (green) and Tau ${ }^{\mathrm{P} 301 \mathrm{~L}}$ (blue). The 3D structures show the repulsion residues (red) and stable residues (blue). While the 2D maps show hydrophobic and electrostatic interaction at the 301 residues.

Figure S3. Electrostatic Potential (ESP) surfaces of the Tau proteins obtained at the final of molecular dynamic simulations. The red color indicates nucleophilic regions; the blue color indicates electrophilic regions; and the white indicates hydrophobic regions. The ESP units used was $k_{B} T / e$, where $k_{B}$ is the Boltzmann constant; T was the MDS temperature, and $e$ was the electron charge. The ESP results were mapped on the protein surfaces at 2.0 isodensity values.
(A) Tau wild type protein.
(B) $\mathrm{Tau}^{\mathrm{P} 301 \mathrm{~L}}$ protein, and 
(C) TauP301S protein.

Figure S4. Energy analysis of the R2-R3 domains.

(A) RMSD plot of Tau 3D structures obtained after 500 ns of MD simulations.

(B) Final alignment of the R2-R3 domains using the 3D structure of the Tau wild-type (orange), $\mathrm{Tau}^{\mathrm{P} 301 \mathrm{~S}}$ (green) and Tau ${ }^{\mathrm{P} 301 \mathrm{~L}}$ (blue).

(C) Radius of gyration plot shows the folding of the Tau 3D proteins

(D) Construction of the free energy landscape maps (FELs) using the data obtained from the RMSD and radius of gyration as variables. The figure only shows the results obtained for the R2 and R3 domains from the last 100ns of simulation.

(E) Energy interactions of R2-R3 domains.

Figure S5. S262 site molecular analysis.

(A) Energetic molecular interactions and SASA on the Tau protein surfaces. The Tau P301L protein shows the greatest solvent accessible area and bigger destabilization energy compared to other Tau proteins.

(B) Energy contribution per residue in the interactions with the S262 residue. The blue box indicates interaction regions. 
bioRxiv preprint doi: https://doi.org/10.1101/2021.04.13.439741; this version posted April 14, 2021. The copyright holder for this preprint (which was not certified by peer review) is the author/funder. All rights reserved. No reuse allowed without permission.

Figure 1.

A

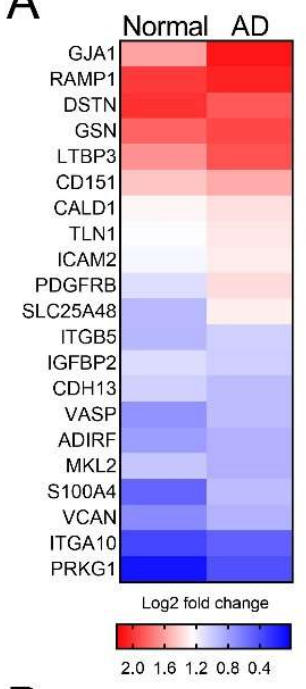

D

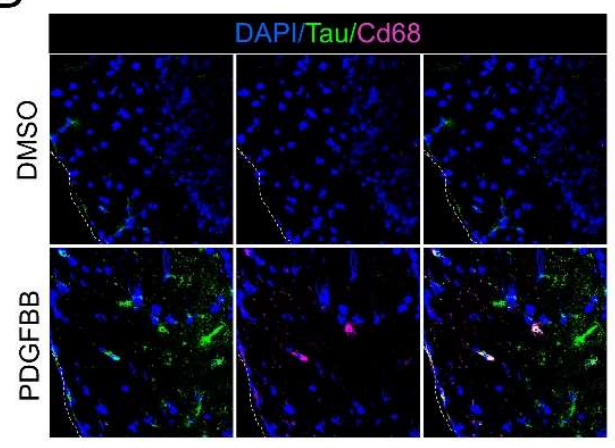

E
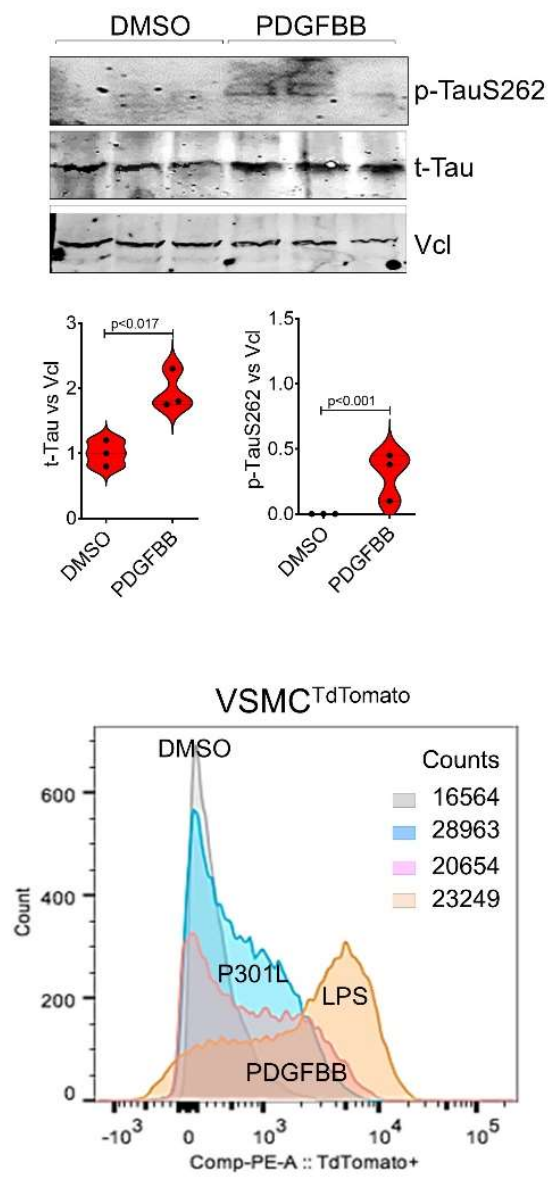

C

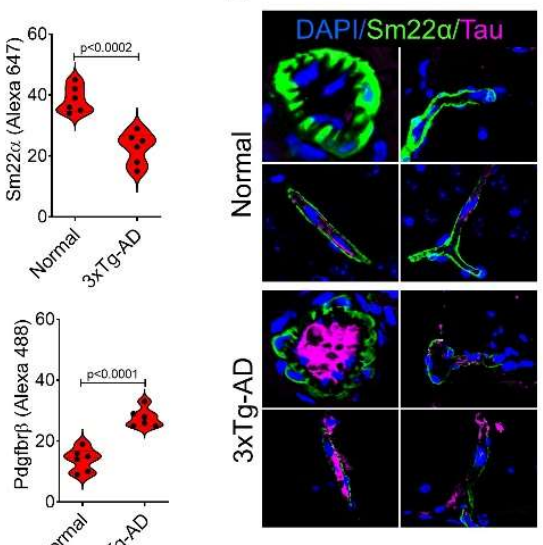

G

F Log2 (Fold change)

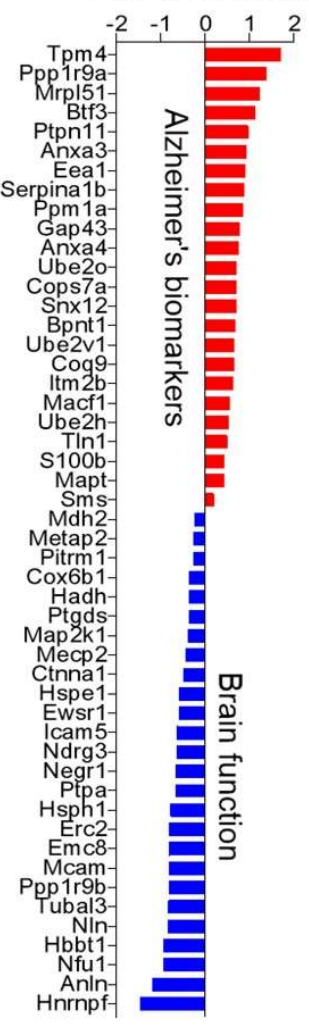

$\mathrm{H}$
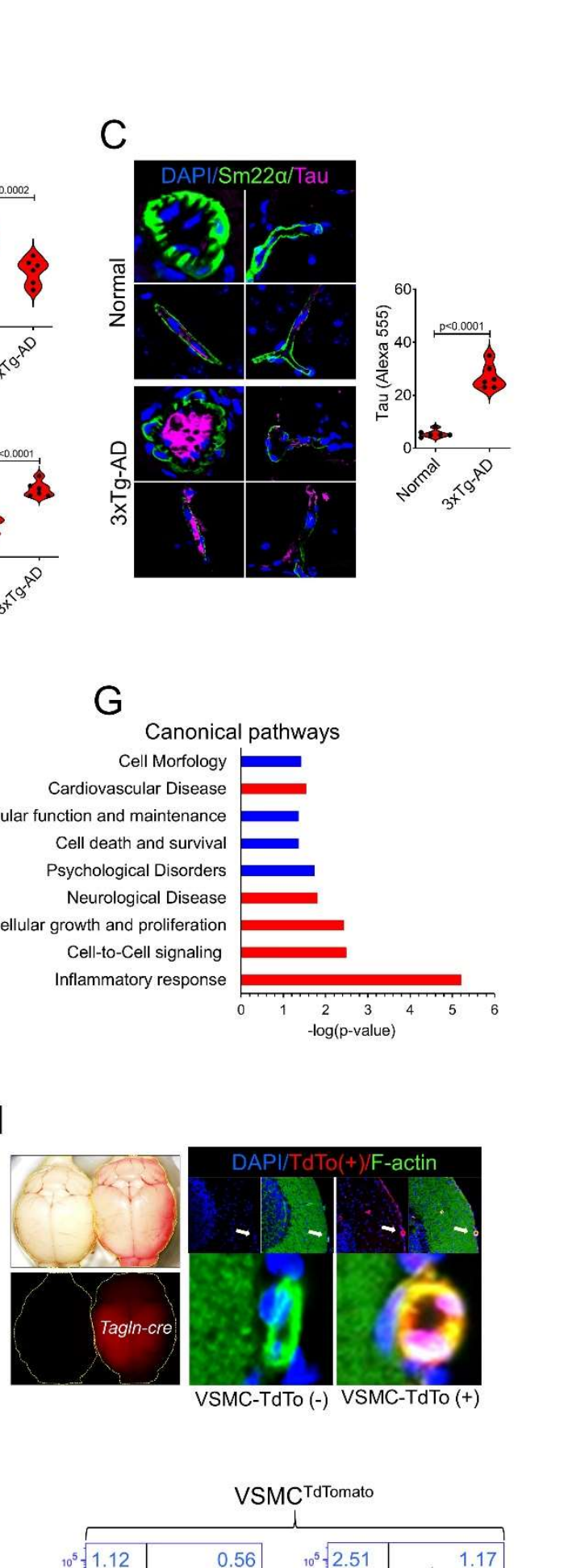

VSMC-TdTo (-) VSMC-TdTo (+)
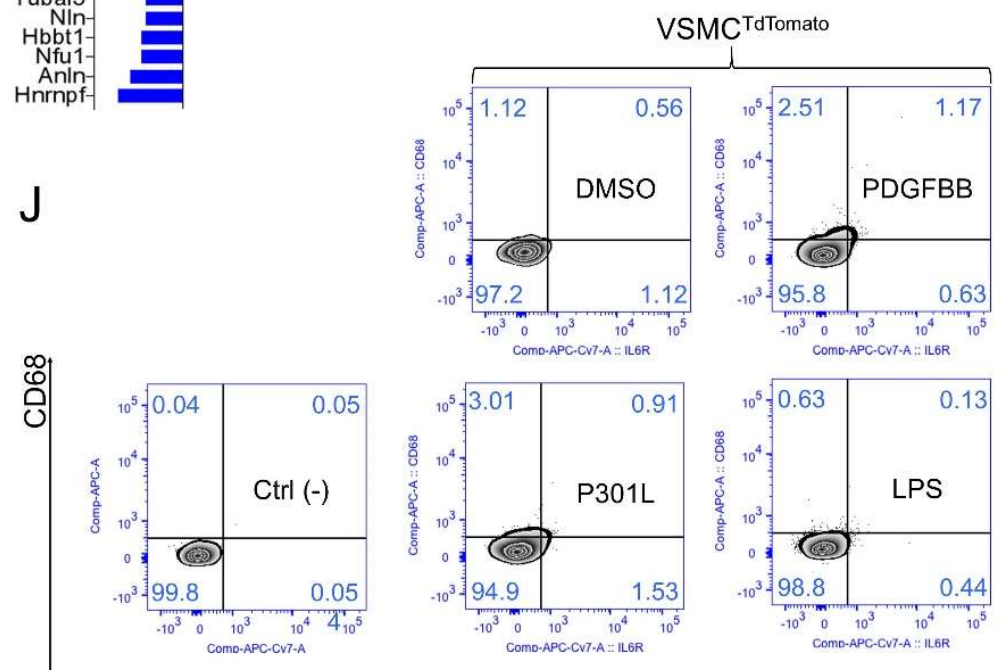

Canonical pathways Cell Morfology

Cardiovascular Disease

Cell death and survival

Psychological Disorders Neurological Disease Cell-to-Cell signaling Inflammatory response

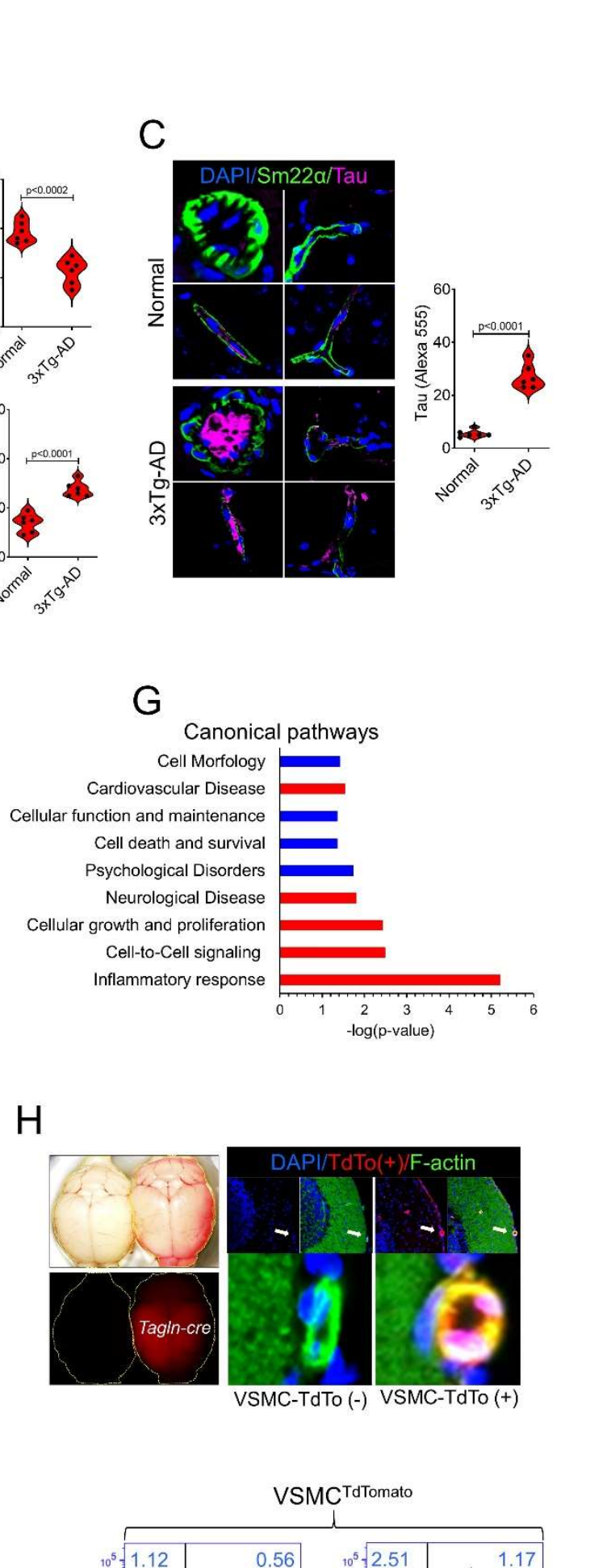

J

VSMC TdTomato

Hnrnpf-

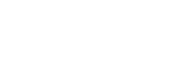

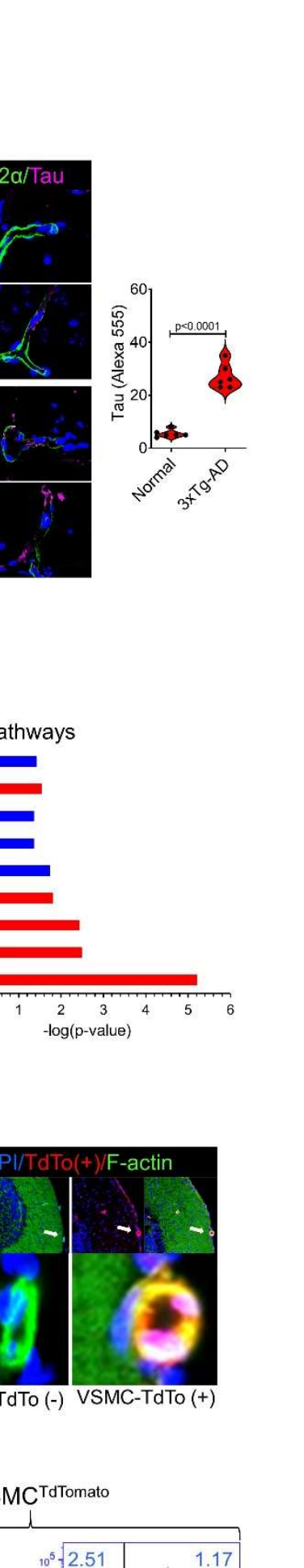


Figure 2.

A
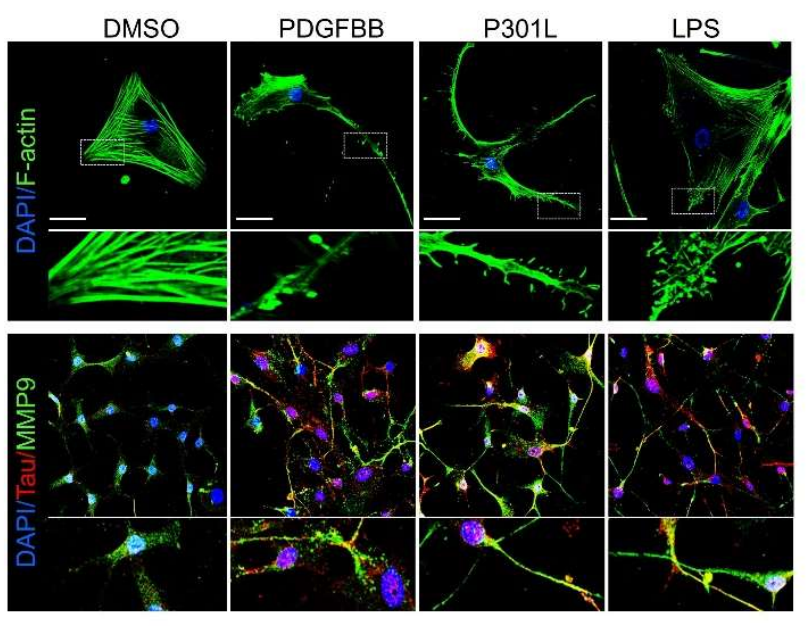

B

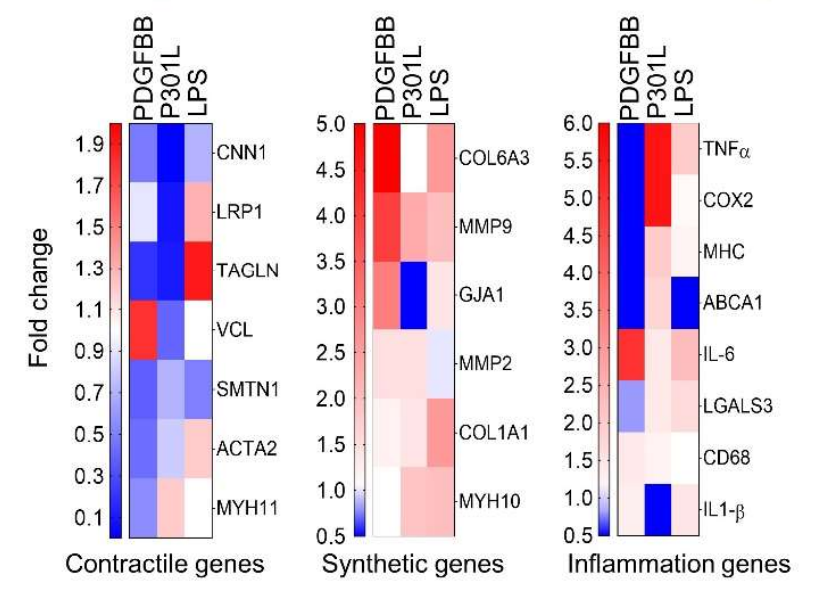

C

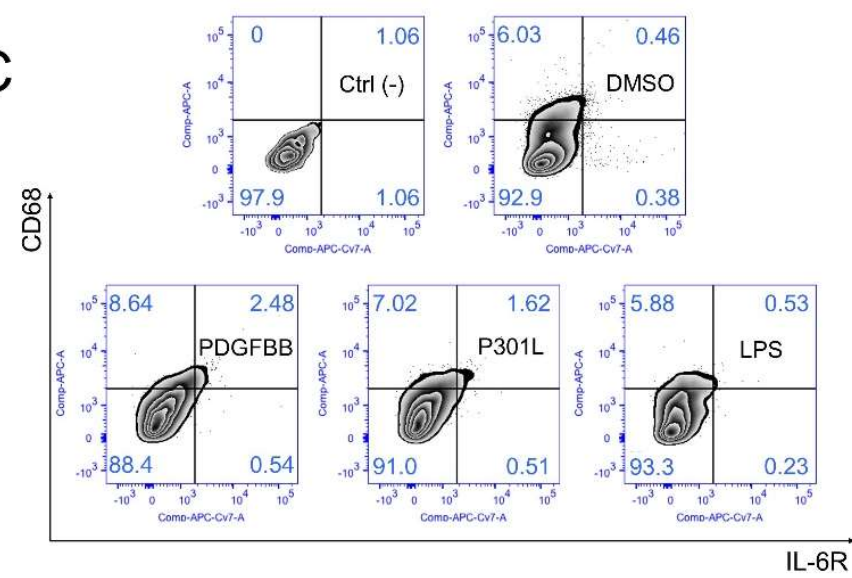

D
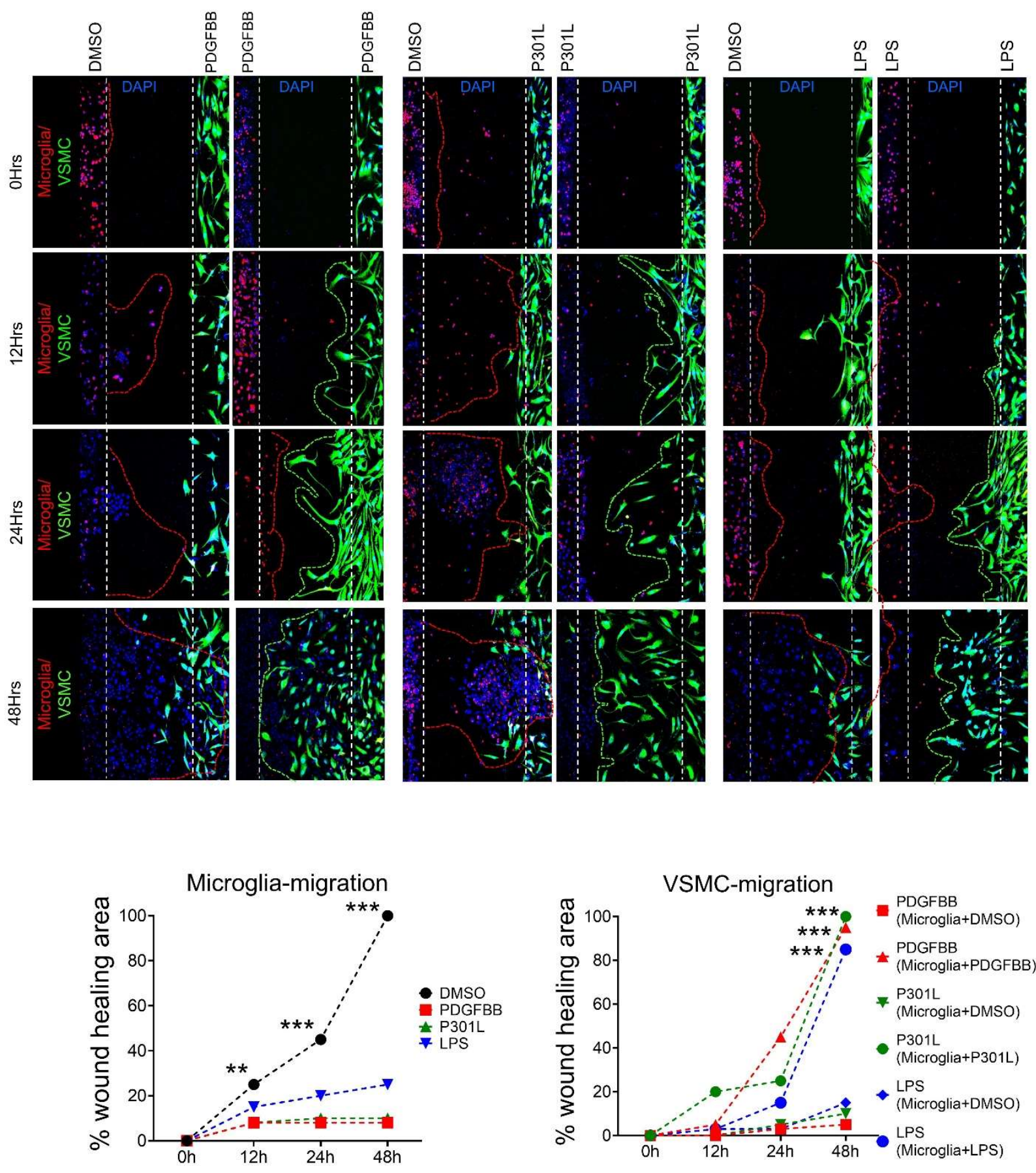

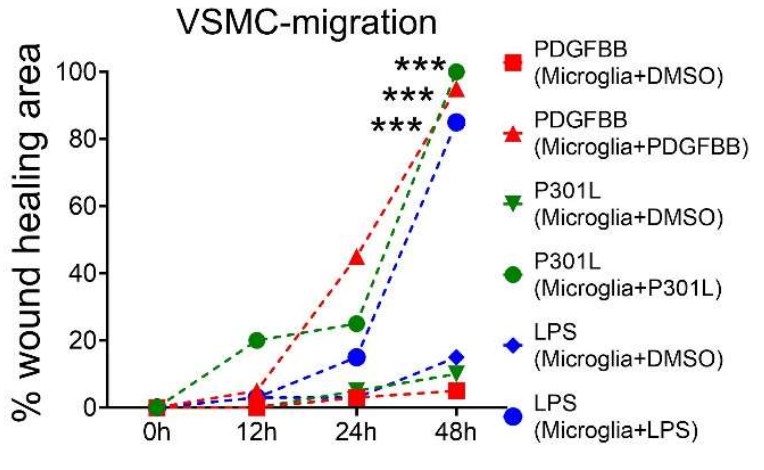


Figure 3.

A
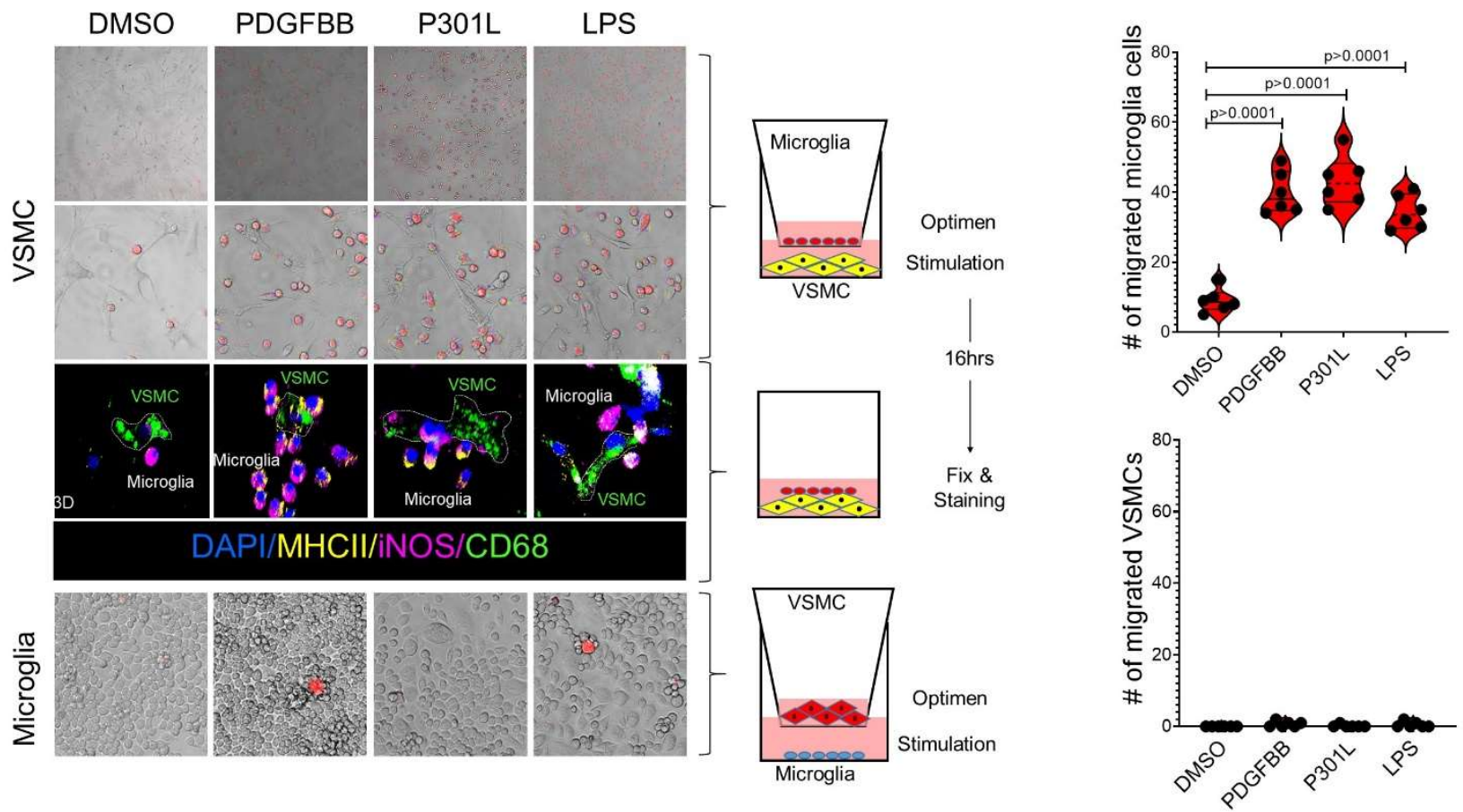

B

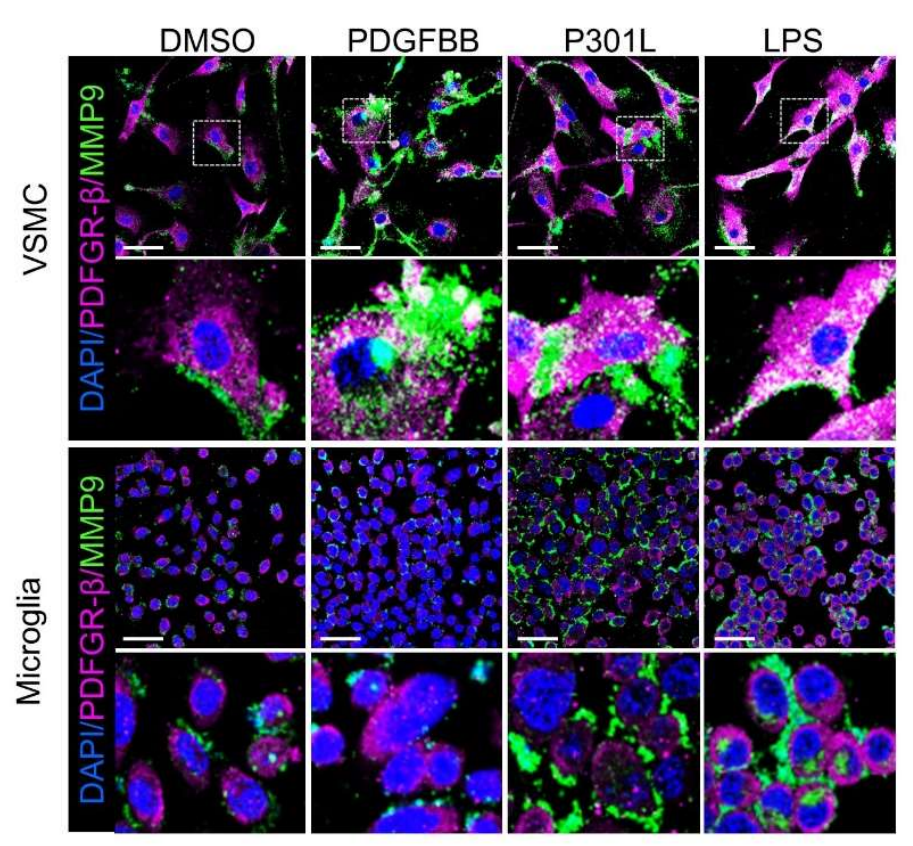

C
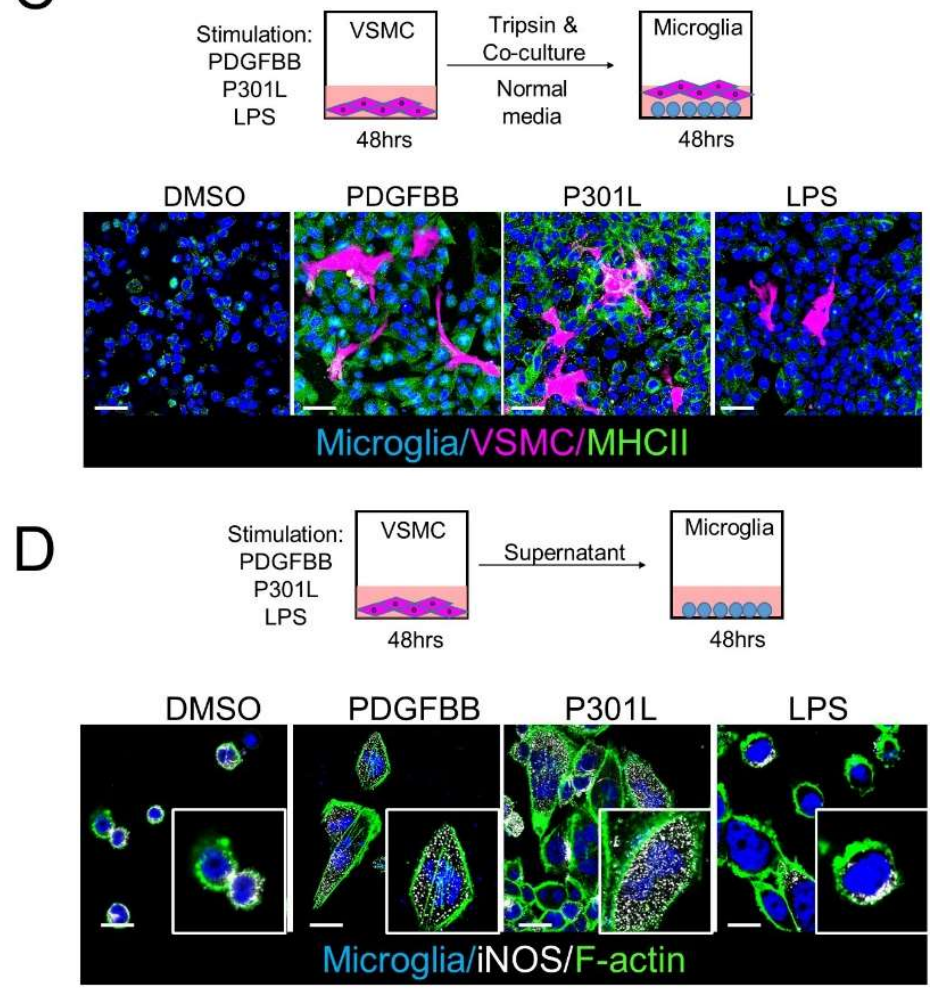
bioRxiv preprint doi: https://doi.org/10.1101/2021.04.13.439741; this version posted April 14, 2021. The copyright holder for this preprint (which was not certified by peer review) is the author/funder. All rights reserved. No reuse allowed without permission.

\section{Figure 4.}

A

$$
\begin{aligned}
& \text { — Tau Wild-type } \\
& \text { — Tau P301L }
\end{aligned}
$$
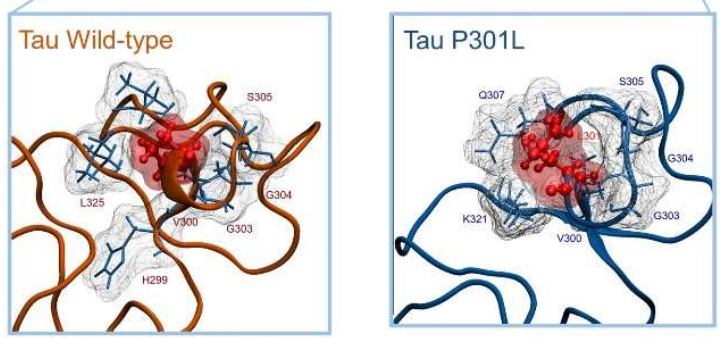

B

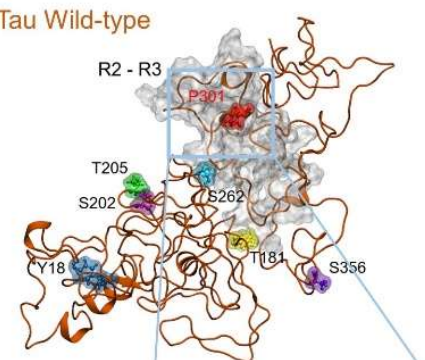

Tau P301L
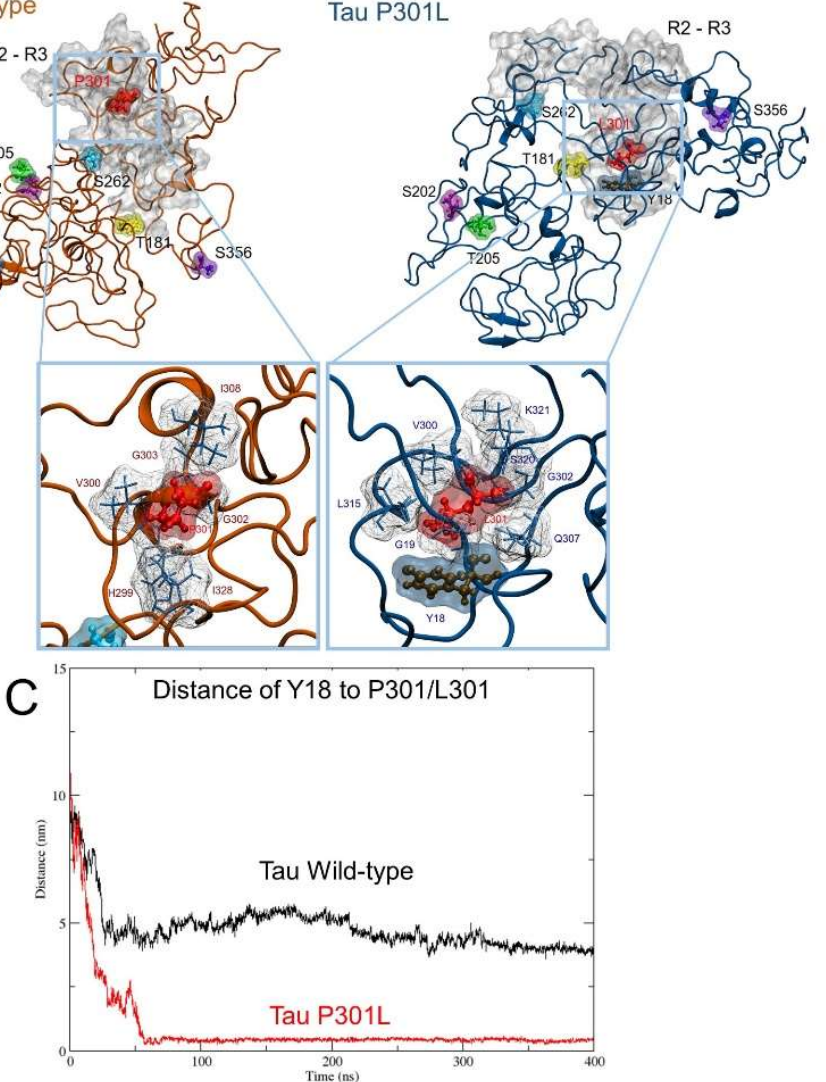

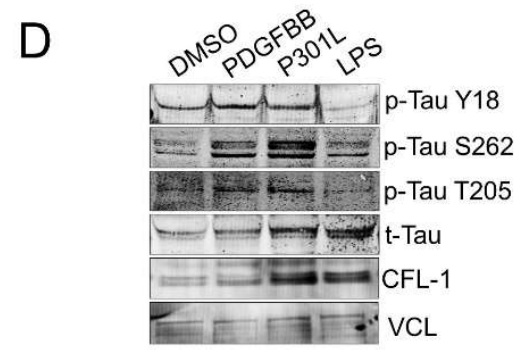

E

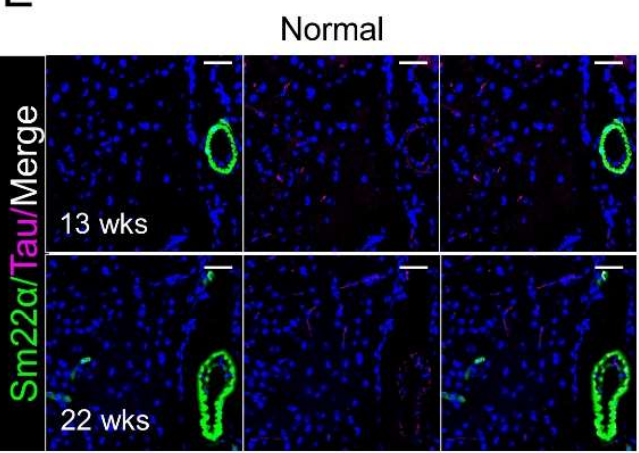

Normal

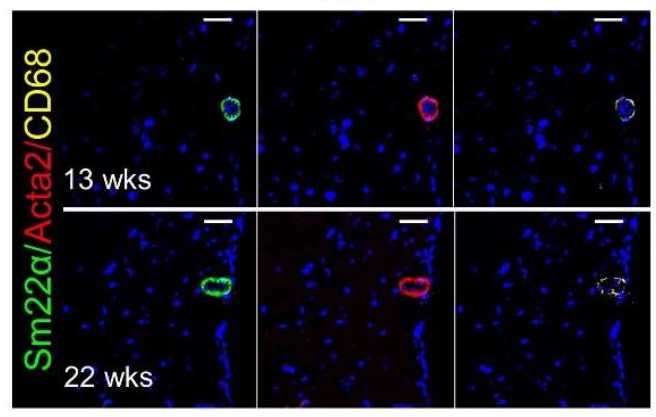

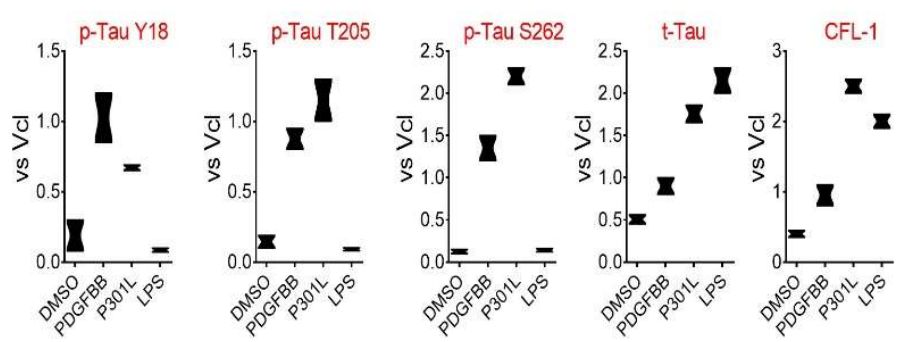

$3 \times T g-A D$

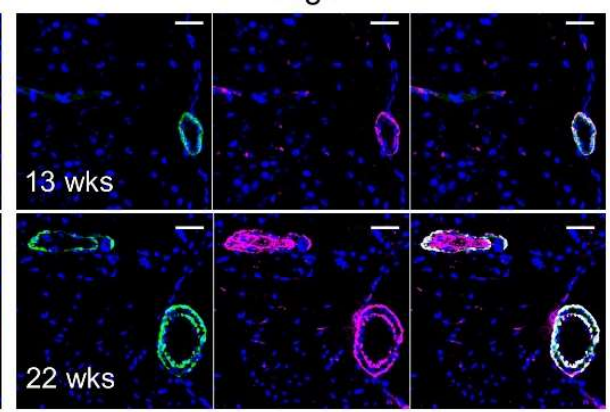

$3 x T g-A D$
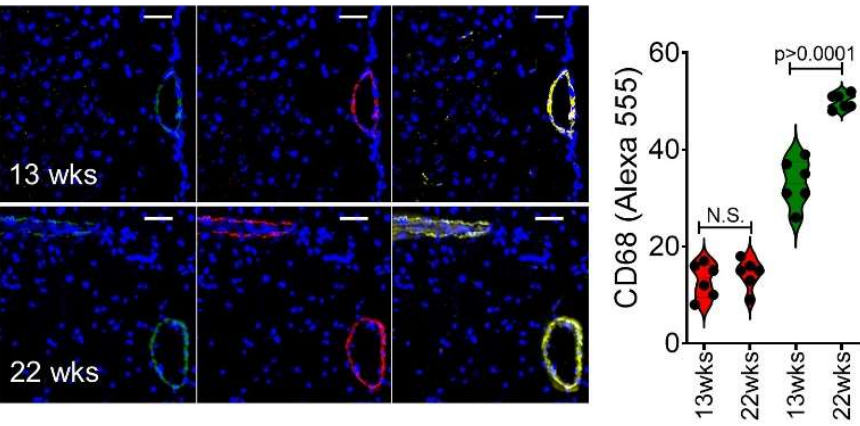

Normal

3xTg-AD 
bioRxiv preprint doi: https://doi.org/10.1101/2021.04.13.439741; this version posted April 14, 2021. The copyright holder for this preprint (which was not certified by peer review) is the author/funder. All rights reserved. No reuse allowed without permission.

\section{SUPPLEMENTARY MATERIAL}

\section{Figure S2}

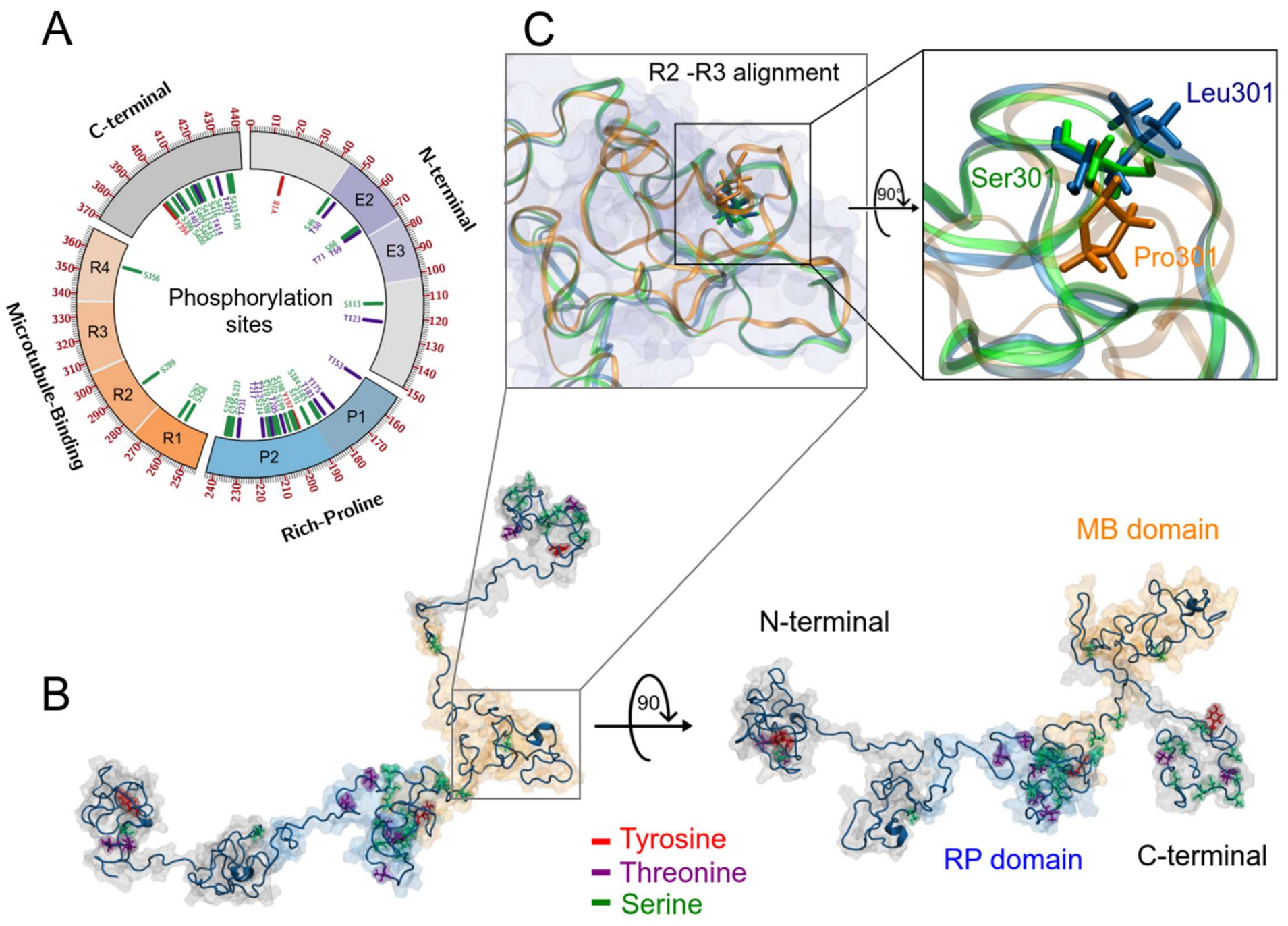


bioRxiv preprint doi: https://doi.org/10.1101/2021.04.13.439741; this version posted April 14, 2021. The copyright holder for this preprint (which was not certified by peer review) is the author/funder. All rights reserved. No reuse allowed without permission.

\section{Figure S3}

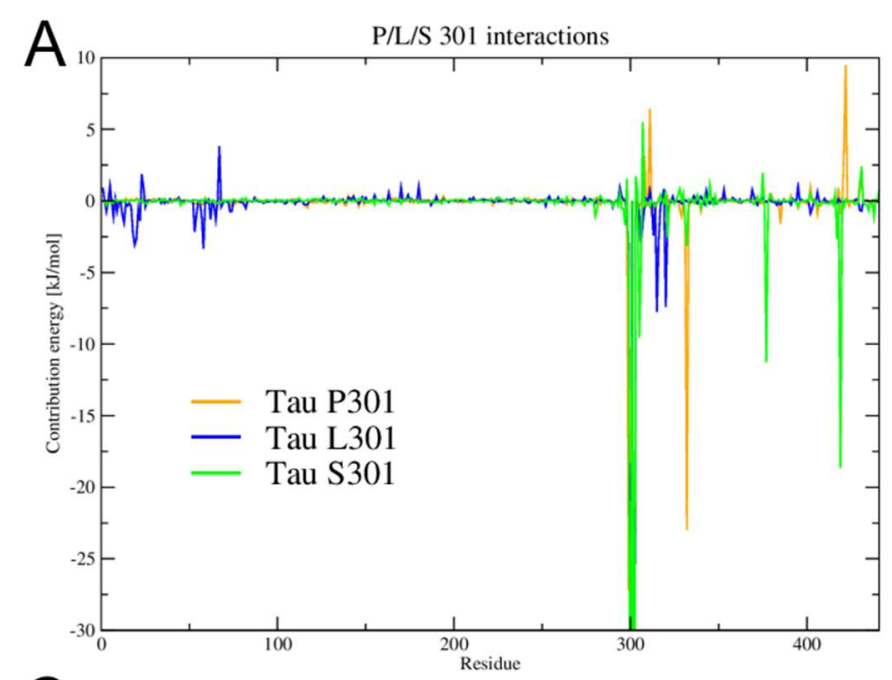

C

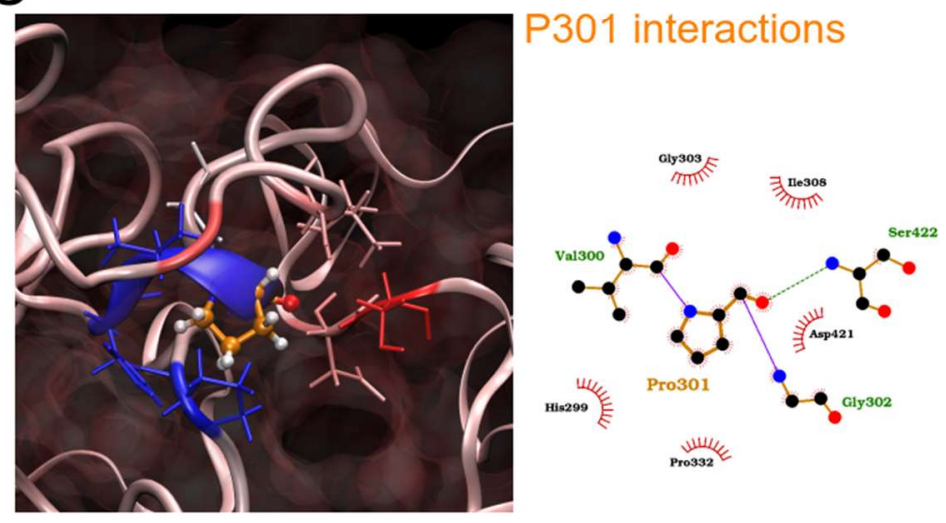

$\mathrm{D}$

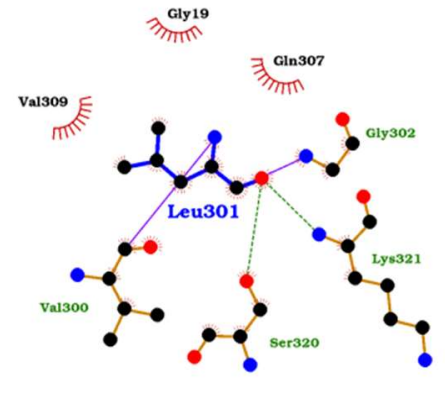

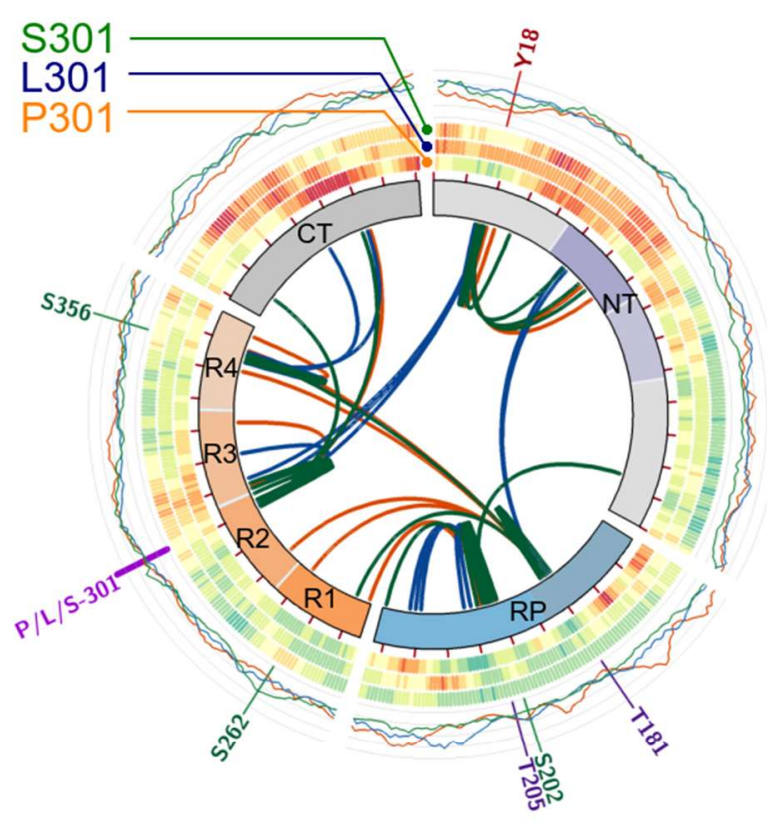

B
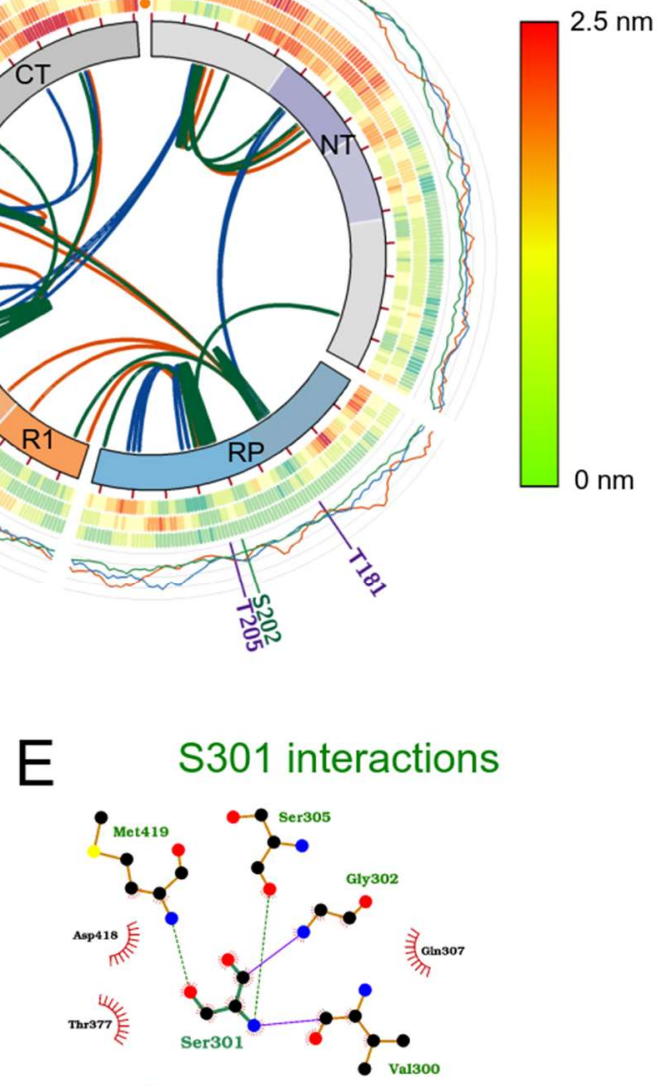

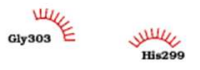

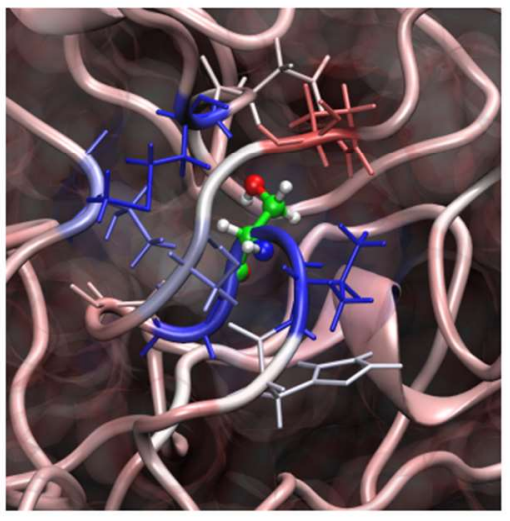




\section{Figure S4}

A

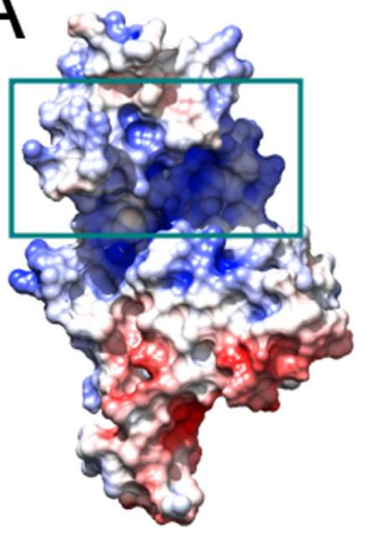

B

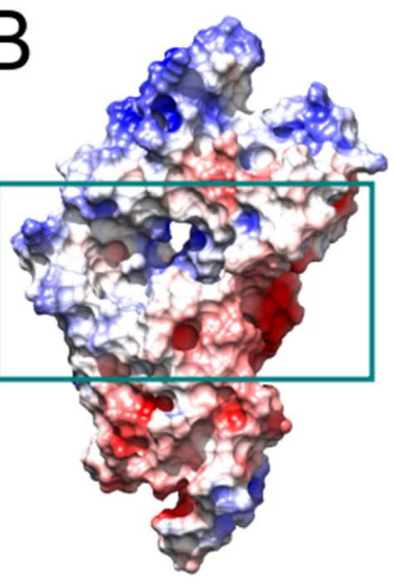

C

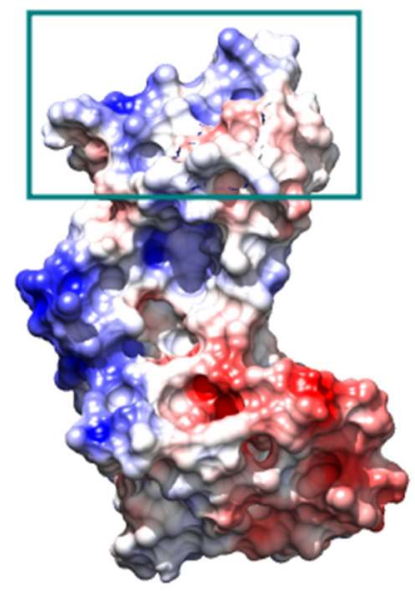

\section{R2 - R3 domains}
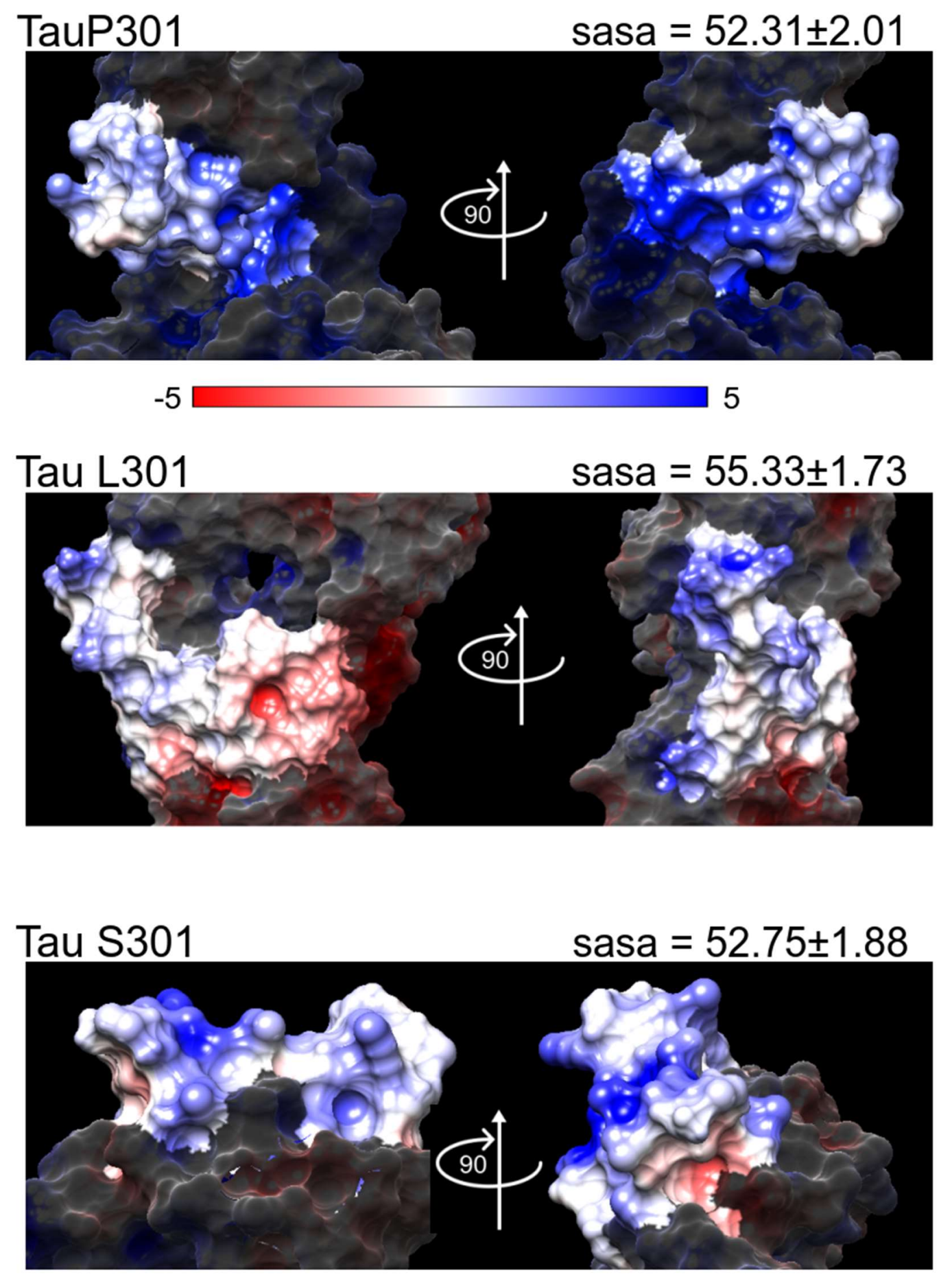
bioRxiv preprint doi: https://doi.org/10.1101/2021.04.13.439741; this version posted April 14, 2021. The copyright holder for this preprint (which was not certified by peer review) is the author/funder. All rights reserved. No reuse allowed without permission.

\section{Figure S5}
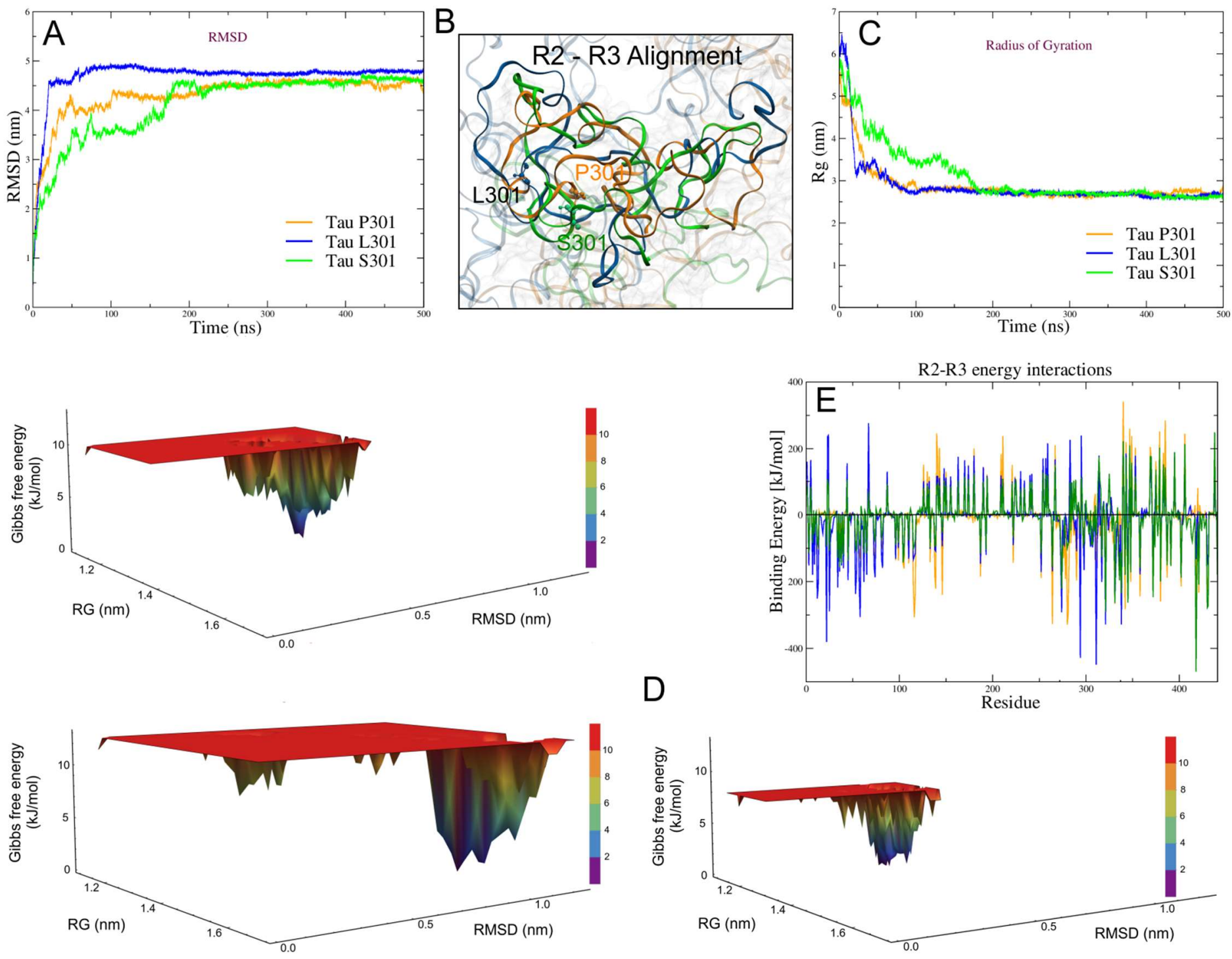
bioRxiv preprint doi: https://doi.org/10.1101/2021.04.13.439741; this version posted April 14, 2021. The copyright holder for this preprint (which was not certified by peer review) is the author/funder. All rights reserved. No reuse allowed without permission.

\section{Figure S6}
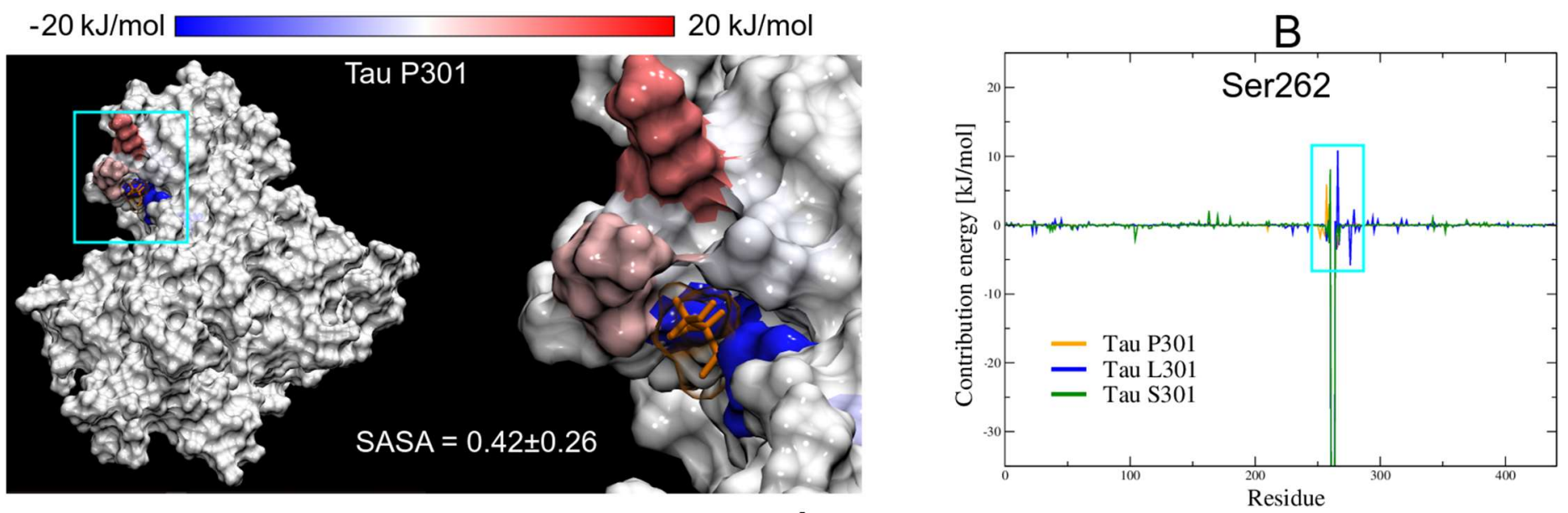

A
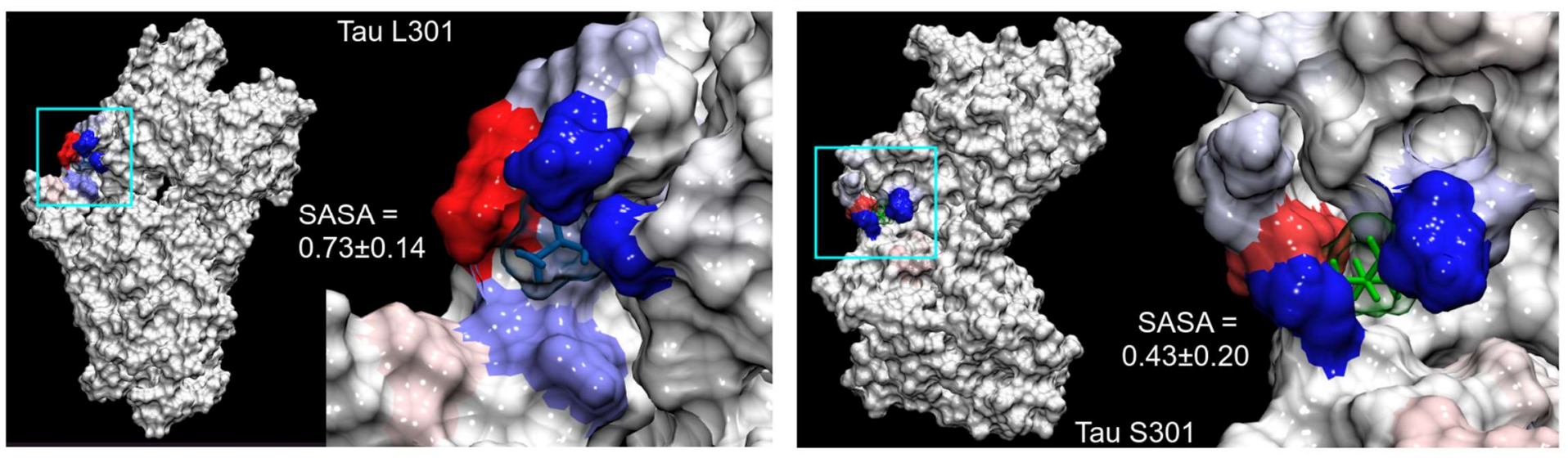


\section{Table S1}

System Details

\begin{tabular}{ccccc}
\hline System & Total atoms & $\begin{array}{c}\text { Protein } \\
\text { atoms }\end{array}$ & $\begin{array}{c}\text { Solvent } \\
\text { molecules }\end{array}$ & Box size \\
\hline Tau P301 & 300427 & 6416 & 98003 & $16.98 \times 15.14 \times 11.71$ \\
Tau L301 & 294825 & 6421 & 96134 & $16.74 \times 15.47 \times 11.39$ \\
Tau S301 & 318859 & 6413 & 104148 & $17.11 \times 15.84 \times 11.77$
\end{tabular}

Stability Descriptors

\begin{tabular}{cccccc}
\hline \multirow{2}{*}{ System } & \multirow{2}{*}{ RMSD } & \multirow{2}{*}{ RMSF } & Radius of & \multicolumn{2}{c}{ H Bonds } \\
\cline { 5 - 6 } & & & Gyration & Intra & Inter \\
\hline Tau P301 & $4.23 \pm 0.64$ & $1.30 \pm 0.45$ & $2.95 \pm 0.60$ & $209 \pm 21$ & $1142 \pm 53$ \\
Tau L301 & $4.58 \pm 0.74$ & $1.29 \pm 0.40$ & $2.99 \pm 0.83$ & $228 \pm 26$ & $1098 \pm 70$ \\
Tau S301 & $4.12 \pm 0.70$ & $1.16 \pm 0.50$ & $3.10 \pm 0.69$ & $218 \pm 15$ & $1124 \pm 41$
\end{tabular}

\section{Table S2. Surface areas}

Solvent accessible surface areas ( $\mathrm{nm} 2)$

\begin{tabular}{|c|c|c|c|c|c|c|c|c|c|c|}
\hline Tau & Protein & $\begin{array}{l}\text { Total } \\
\text { area }\end{array}$ & R2 - R3 & Tyr18 & Thr181 & Ser202 & Thr 205 & Ser262 & X301 & Ser356 \\
\hline \multirow{2}{*}{ P301 } & final val. & $269.79 \pm 6.10$ & $52.31 \pm 2.01$ & $0.87 \pm 0.25$ & $0.31 \pm 0.18$ & $0.56 \pm 0.16$ & $1.09 \pm 0.29$ & $0.42 \pm 0.26$ & $0.55 \pm 0.13$ & $0.96 \pm 0.11$ \\
\hline & Initial val. & 360.99 & 46.05 & 0.22 & 1.00 & 1.16 & 0.31 & 0.82 & 0.29 & 0.93 \\
\hline \multirow{2}{*}{ L301 } & final val. & $240.31 \pm 4.65$ & $55.33 \pm 1.73$ & $0.28 \pm 0.20$ & $0.26 \pm 0.10$ & $0.17 \pm 0.13$ & $0.55 \pm 0.10$ & $0.73 \pm 0.14$ & $0.11 \pm 0.06$ & $0.04 \pm 0.03$ \\
\hline & Initial val. & 361.59 & 51.94 & 1.72 & 1.09 & 0.77 & 0.16 & 0.84 & 0.78 & 0.24 \\
\hline \multirow{2}{*}{ S301 } & final val. & $250.35 \pm 5.80$ & $52.75 \pm 1.88$ & $0.22 \pm 0.17$ & $0.12 \pm 0.06$ & $0.23 \pm 0.14$ & $0.42 \pm 0.11$ & $0.43 \pm 0.20$ & $0.13 \pm 0.05$ & $0.23 \pm 0.11$ \\
\hline & Initial val. & 362.33 & 52.05 & 1.54 & 1.07 & 0.95 & 0.17 & 0.88 & 0.31 & 0.26 \\
\hline
\end{tabular}



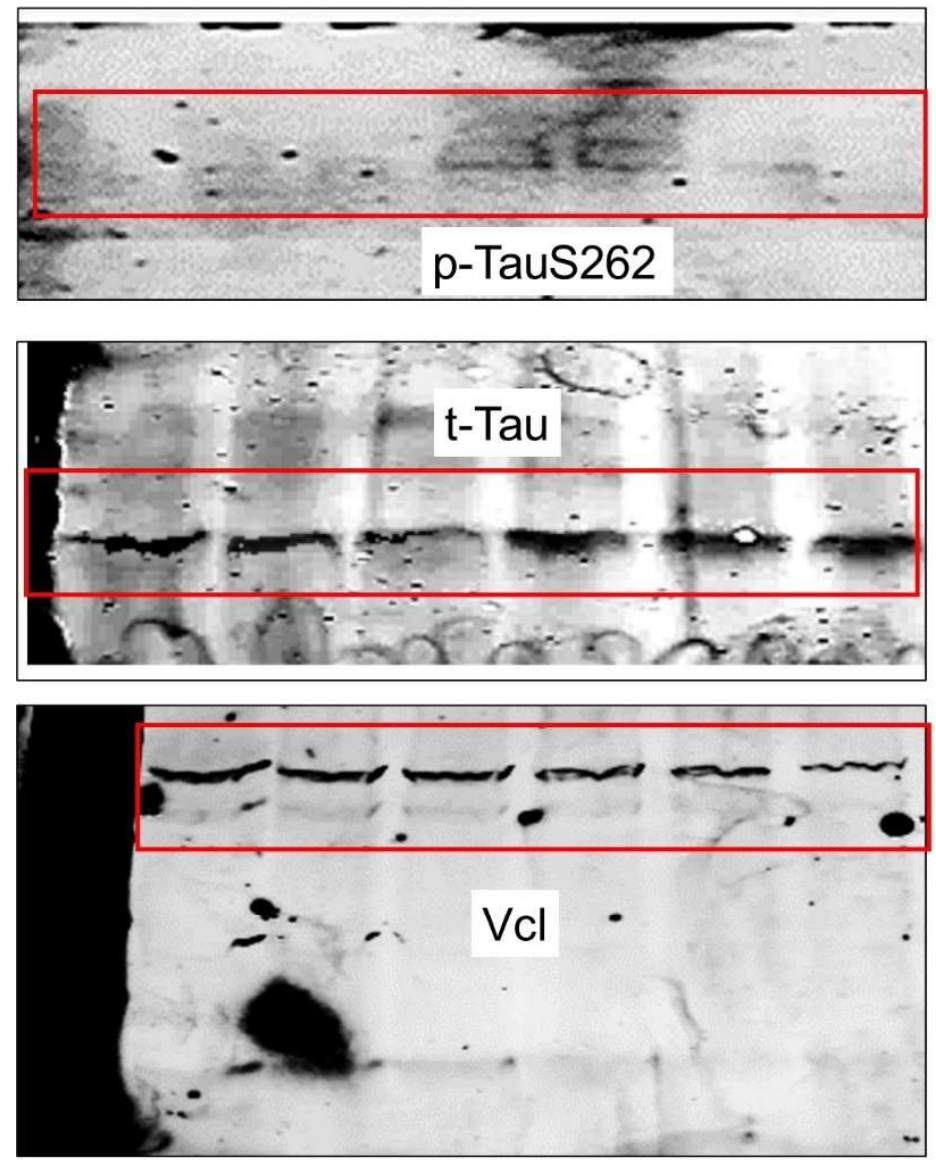
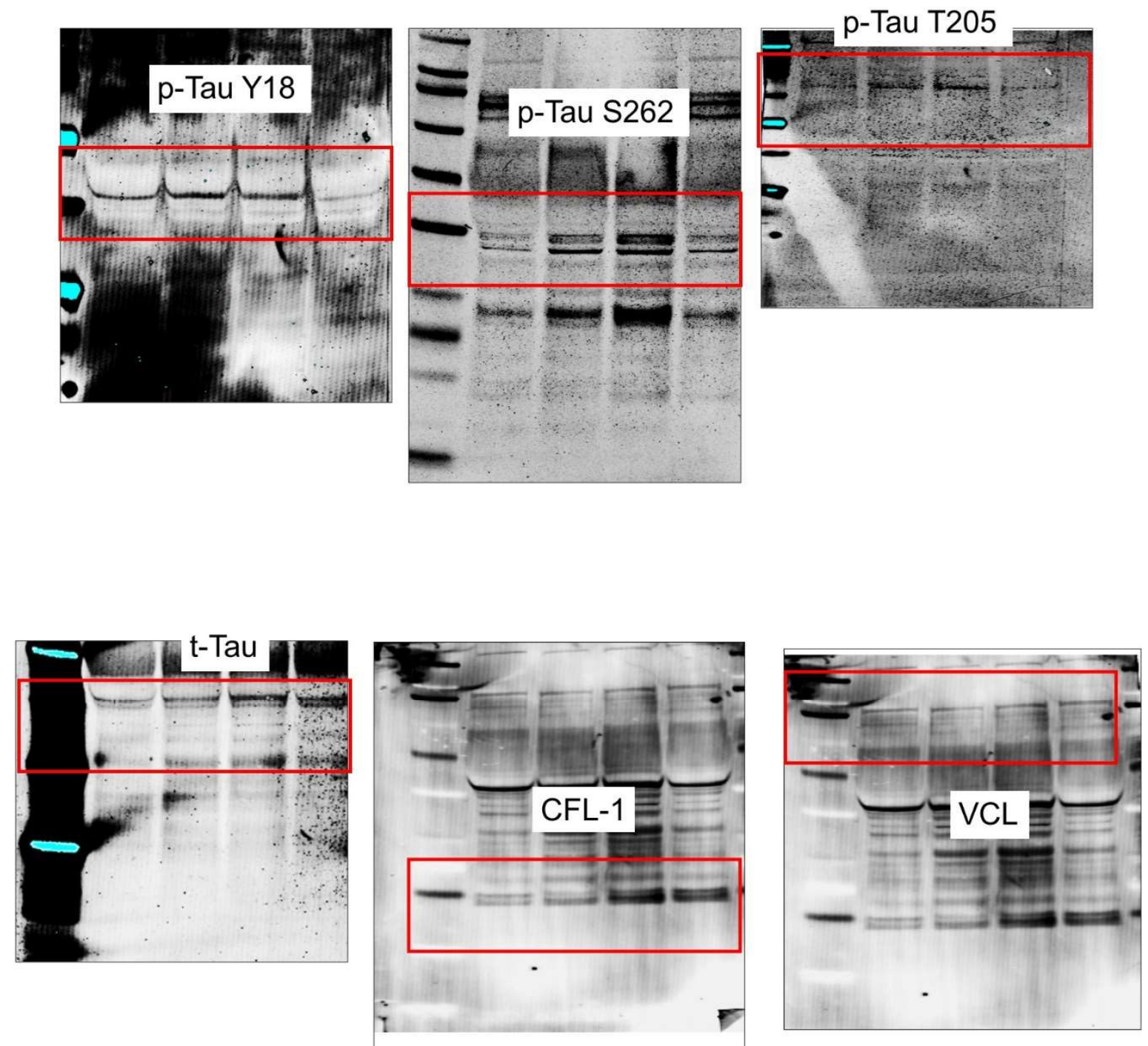